\title{
Verification of the Optimizing NOABL Model Using a Spatially Dense Wind Data Set
}

\author{
J. C. Barnard
}

A. Germain

April 1988

Prepared for the U.S. Department of Energy under Contract DE-AC06-76RLO 1830

Pacific Northwest Laboratory Operated for the U.S. Department of Energy by Battelle Memorial Institute 


\section{DISCLAIMER}

This report was prepared as an account of work sponsored by an agency of the United States Government. Neither the United States Government nor any agency thereof, nor Battelle Memorial Institute, nor any or their employees, makes any warranty, expressed or implied, or assumes any legal liability or responsibility for the accuracy, completeness, or usefulness of any information, apparatus, product, or process disclosed, or represents that its use would not infringe privately owned rights. Reference herein to any specific commercial product, process, or service by trade name, trademark, manufacturer, or otherwise does not necessarily constitute or imply its endorsement, recommendation, or favoring by the United States Government or any agency thereof, or Battelle Memorial Institute. The views and opinions of authors expressed herein do not necessarily state or reflect those of the United States Government or any agency thereof, or Battelle Memorial Institute.

\section{PACIFIC NORTHWEST LABORATORY operated by \\ BATTELLE MEMORIAL INSTITUTE for the UNITED STATES DEPARTMENT OF ENERGY under Contract DE-AC06-76RLO 1830}

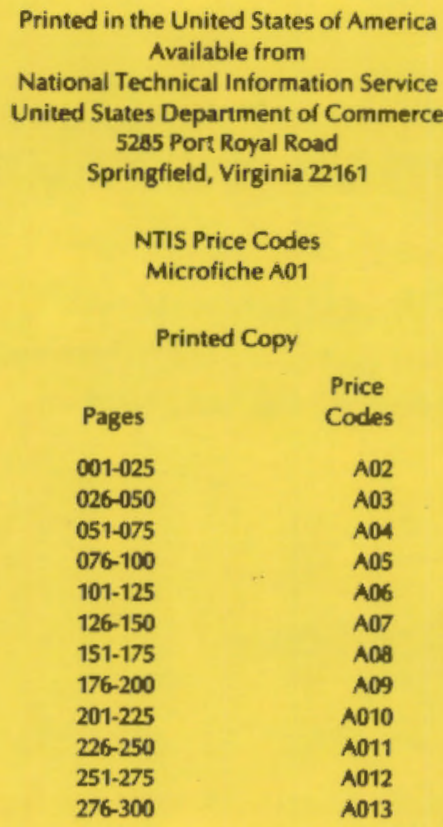


VERIFICATION OF THE OPTIMIZING NOABL MODEL USING A SPATIALLY DENSE WIND DATA SET

J. C. Barnard

A. Germain(a)

Apri1 1988

Prepared for the U.S. Department of Energy under Contract DE-AC06-76RL0 1830

Pacific Northwest Laboratory Richland, Washington 99352

(a) Flowind Corporation Pleasanton, California 



\section{SUMMARY}

This report examines the ability of a numerical model--the optimizing NOABL mode1--to predict wind speeds and gross turbine power outputs over an area of complex terrain. To achieve this end, wind observations from a data set of high spatial density are compared to model predictions of the wind. Additionaliy, gross turbine powers, derived from the wind observations, are compared to the same quantity calculated from model-derived wind speeds.

The model is operated using two approaches. With the first approach, the model is operated repeatedly in an attempt to construct wind speed frequency distributions over the modeled area; from these distributions mean speeds and gross powers are determined. With the second approach, the model is run only once using mean speeds as input. When the first approach is used, it is found that the wind speed and turbine power prediction errors are about $5 \%$ and $11 \%$, respectively. When the second approach is employed, the wind speed and power prediction errors are about $5 \%$ and 13\%, respectively. (Because the gross turbine power does not include many factors that influence turbine performance, the error in model predictions of actual turbine power is likely to be substantially higher, although this is no fault of the model.)

Two other aspects of model application are also briefly investigated. First, it is found that the modeling results are sensitive to the location of the tuning sites; second, values of the model's stability parameter, $\tau$, and the calculated wind direction, $\theta$, derived for one modeling domain, are not transferrable to a nearby domain. 



\section{ACKNOWLEDGMENTS}

The authors would like to thank the many people who contributed to this report. Ruth Keefe did an excellent job in both the typing and layout of this manuscript. Elizabeth Owczarski provided the editorial help that contributed to the clarity of the text. Drs. Larry Wendell and Chris Doran contributed many helpful technical suggestions. The external reviewers, Drs. Scott Veenhuizen, Paul Veers, and Ed McCarthy, also provided many valuable recommendations that greatly improved the quality of the report. Martin LeRoy is thanked for his efforts in providing us with wind direction data in a very timely manner. 



\section{CONTENTS}

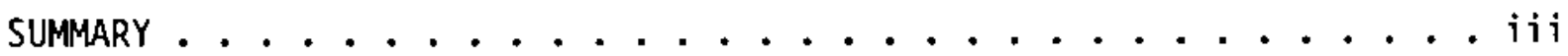

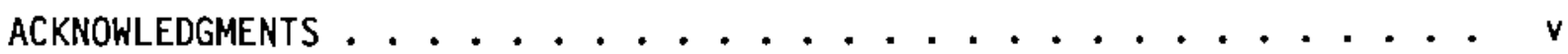

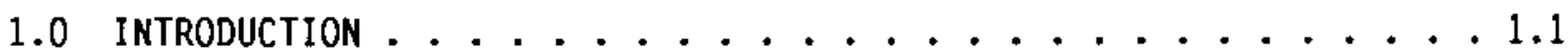

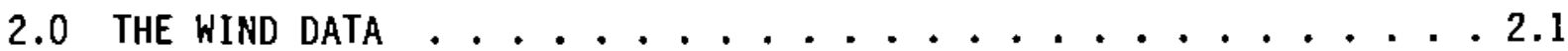

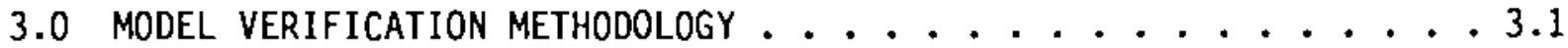

3.1 SELECTION OF THE AREA TO BE MODELED . . . . . . . . 3.1

3.2 SELECTION OF the TUNING AND VERIfICATION SITES $\ldots . \ldots .2$

3.3 CALCULATION OF the AVERAGE GROSS POWER . . . . . . 3.6

3.4 DATA SUMMARIZATION . . . . . . . . . . . 3.7

3.4.1 Random Methods . . . . . . . . . . 3.8

3.4 .2 Using Mean Data . . . . . . . . . 3.13

3.5 COMPARISON OF THE MODEL RESULTS TO THE OBSERVATIONS . . . 3.14

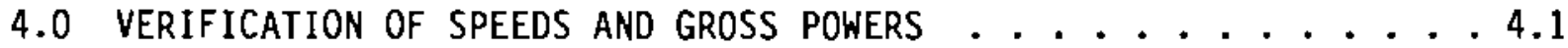

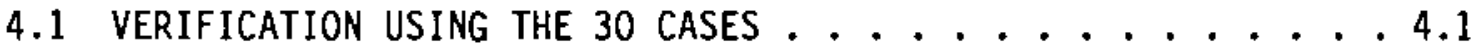

4.2 Verification USING MEAN DATA .......................

5.0 IMPORTANT POINTS ABOUT MODEL APPLICATION ......... 5.1

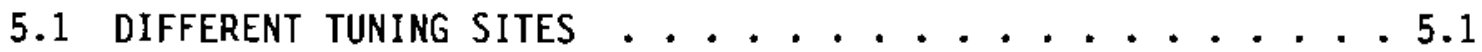

5.2 CORRELATION BETWEEN MODEL PARAMETERS OBTAINED

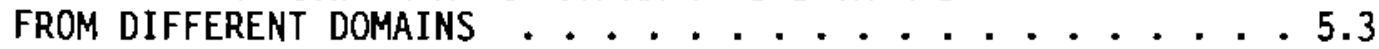

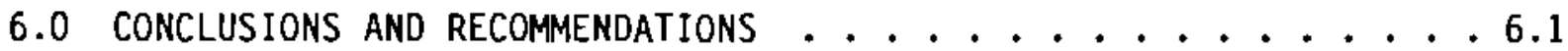

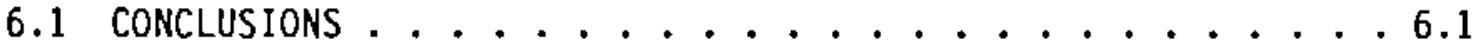

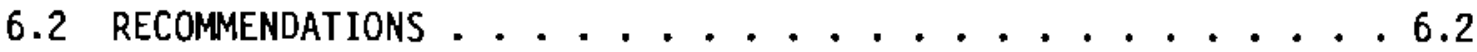

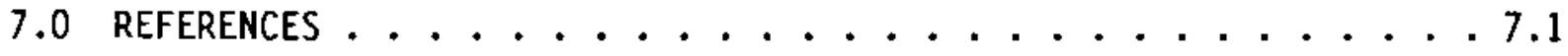
APPENDIX A - WIND SPEED FREQUENCY DISTRIBUTIONS . . . . . . . . A.1 APPENDIX B - MODELED AND MEASURED WINO SPEED FREQUENCY

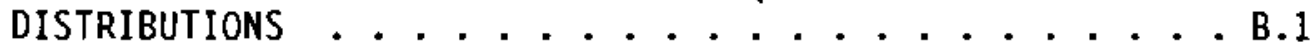




\section{FIGURES}

1 Terrain Contour Map with Wind Observation Sites Indicated by the Black Diamonds ............. 2.1

2 Time Series of the Hourly Averaged Wind Speeds for Wind observation Site 1301 During August 1985 . . . . . . 2.2

3 Averaged Daily Kind Directions for Stations 1326 and $1394 \ldots 2.3$

4 The $\mathrm{NW}$ and $\mathrm{SW}$ Modeling Domains .............. 3.5

5 A Turbine Power-Versus-Speed Curve Used to Calculate Observed Average Gross Powers ............. . 3.7

6 Discrete and Smoothed Frequency Distributions for the Average Speed at the 12 Tuning Sites . . . . . . . 3.10

7 Scatter Plot of Power RMSE of the Verification Sites Versus the Power RMSE of the Tuning Sites for the 50 Sets of 30 Hourly Cases Selected at Random . . . . . . . 3.12

8 Monthly Averaged Power Plotted Versus Monthly Averaged Speed for the 51 Stations with a Full 744 Hours of Data; These Stations Comprise the Bulk of Table 1........ 3.14

9 Scatter Plots of the Observed Averaged Speed Versus the Calculated Average Speed for the NW and SW Modeling Domains . . . . . . . . . . . . 4.4

10 Wind Speed Contour Plots for the NW and SW Modeling Domains................ 4.6

11 Scatter Plots of the Observed Average Gross Power Versus the Model-Calculated Average Gross Power for the NW and SW Modeling Domains ................. 4.8

12 Contours for the Average Gross Power for the NW and SW Modeling Domains

13 Model-Predicted Average Gross Powers Plotted Versus

the Observed Average Gross Power for the 26 Verification

Sites for the NW and SW Modeling Domains .......... 4.10

14 Scatter Plots of Measured Wind Direction Versus the Direction Predicted by the Model . . . . . . . . . . 4.12

15 Scatter Plots of the Observed Averaged Speed Versus the Calculated Average Speed for the NW and SW Modeling Domains . . . . . . . . . . . . 4.17 
16 Scatter Plot of the Observed Average Gross Power Versus the Model-Calculated Average Gross Power for the NW Doma in when a Different Set of Tuning Sites is Used for Model Tuning . . . . . . . . . . . 5.3

17 Scatter Plot of the Optimum Value of $\tau$ for the SW Domain Plotted Against the Optimum Value of $\tau$ for the NW Domain, and $\theta$ for the SW Domain Against the Optimum Value of $\theta$ for the NW Domain . . . . . . . . . 5.4 


\section{TABLES}

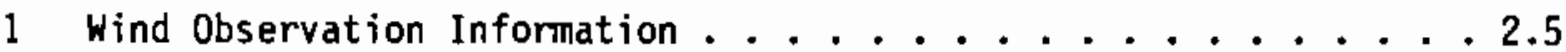

2 Location of Tuning and Verification Sites for the NW

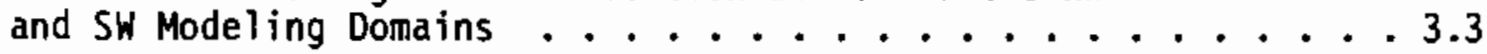

3 Subset of 30 Cases Used to Represent the Flow

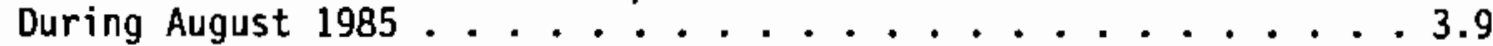

4 Summary of Modeling Results for the 30 Cases ......... 4.2

5 Observed and Calculated Monthly Averaged Wind Speeds . . . . . 4.3

6 Observed and Calculated Monthly Averaged Gross Powers . . . . . 4.7

7 Summary of Modeling Results Using Mean Wind Speeds for Model Input . . . . . . . . . . . . . . 4.14

8 Observed and Calculated Monthly Averaged Speeds and Gross Powers for the NW Domain . . . . . . . . . . . . 4.15

9 Observed and Calculated Monthly Averaged Speeds and Gross Powers for the SW Domain . . . . . . . . . . . . 4.16

10 Observed and Calculated Monthiy Averaged Gross Powers for a Different Set of Tuning Sites . . . . . . . . . 5.2 


\subsection{INTRODUCTION}

Experience obtained in the wind energy industry within the last decade has underscored the need for the careful siting of turbines located in areas of complex terrain. The large spatial variation of the wind that may occur in these areas has caused unexpected power reductions and consequent revenue loss from turbines that have inadvertently been sited in poor locations. The desire to avoid such siting blunders has generated a number of micrositing techniques, one of which is numerical modeling.

of the many types of numerical models that have been used to simulate the atmospheric flow, one of the least complicated is the mass-consistent model. This model works by first constructing an initial wind field based on wind observations over the area in question. Then this initial field is adjusted the minimum amount so as to achieve a final field that is non-divergent; that is, it satisfies the equation of continuity. The amount of relative adjustment in the horizontal and vertical directions is controlled by an empirical stability parameter, $T$. Values of $T$ less than 0 give greater emphas is to flow around a terrain feature rather than over it, thereby imitating stable flow. In an opposite manner, $\tau$ values greater than 0 simulate unstable flow. Neutral flow is simulated when $T$ is $0_{i}$ in this case the adjustment gives no preference to flow over or around a terrain obstacle.

One particular mass-consistent model that has been applied to the micrositing problem is the optimizing NOABL model (Barnard, Hegley and Hiester 1987). This model is an improved version of the NOABL mass-consistent model originally developed by Traci, Phillips and Patnaik (1978). In the original model, the calculated wind field exhibits a large sensitivity to two important input parameters: the empirical stability parameter, $T$, and usually to a lesser extent, the initial wind direction, $\theta$. The initial wind direction is the direction specified for the wind prior to the adjustment to make the field mass consistent. These parameters were supplied to the original model by educated guesswork, and poor guesses often led to highly inaccurate wind fields. To eliminate the need for guessing, the improved model merges an optimization scheme with the original model so that optimum values of $\tau$ and $\theta$ 
can be determined by the optimization procedure. When the optimum parameters are used to calculate the wind field, a significant increase in the accuracy of the wind simulation often occurs.

The optimizing NOABL model has been subject to verification using a limited amount of wind data (Barnard, Wegley and Hiester 1987), namely 8 cases of hourly averaged observations taken at 28 sites over a microscale region of about $4 \mathrm{~km}^{2}$. The results of this verification exercise were quite promising; however, the wind data set used for verification was not considered extensive enough to firmly establish the reliability of the model. Recently a much larger wind data set has been collected; these data provide an unparalleled opportunity for model verification. The data set consists of hourly averaged observations made during the entire month of August 1985 for about 60 stations located in the Altamont Pass area of California. The region over which these observations were taken encompasses an area of about $10 \mathrm{~km}^{2}$. (These wind data were provided to Pacific Northwest Laboratory by Flowind Corporation as part of a cooperative agreement between these two organizations.)

The goal of this report is to perform a further and much more extensive investigation of the behavior of the optimizing NOABL model using this new data set. Model-derived winds will be compared to observed winds to assess the accuracy of the model. Additionally, this study will examine the model's ability to predict the average (gross) power of hypothetical turbines located at the wind observation sites. By considering the exactness of these wind and power predictions, one may speculate as to the suitability of the model for wind turbine micrositing. The true usefulness of the model can only be determined after it has been subject to the rigors of use by the wind energy community. 


\subsection{THE WIND DATA}

The wind data used for model verification consist of wind speeds, which were measured at a height of $13.7 \mathrm{~m}(45 \mathrm{ft})$. The 58 observation sites were distributed over an area of about $10 \mathrm{~km}^{2}$; Figure 1 shows a contour map of this area upon which the station locations are indicated by the black diamonds. (The terrain contours in this figure are in feet, not meters.) The four digits next to the observation sites are the station identification numbers.

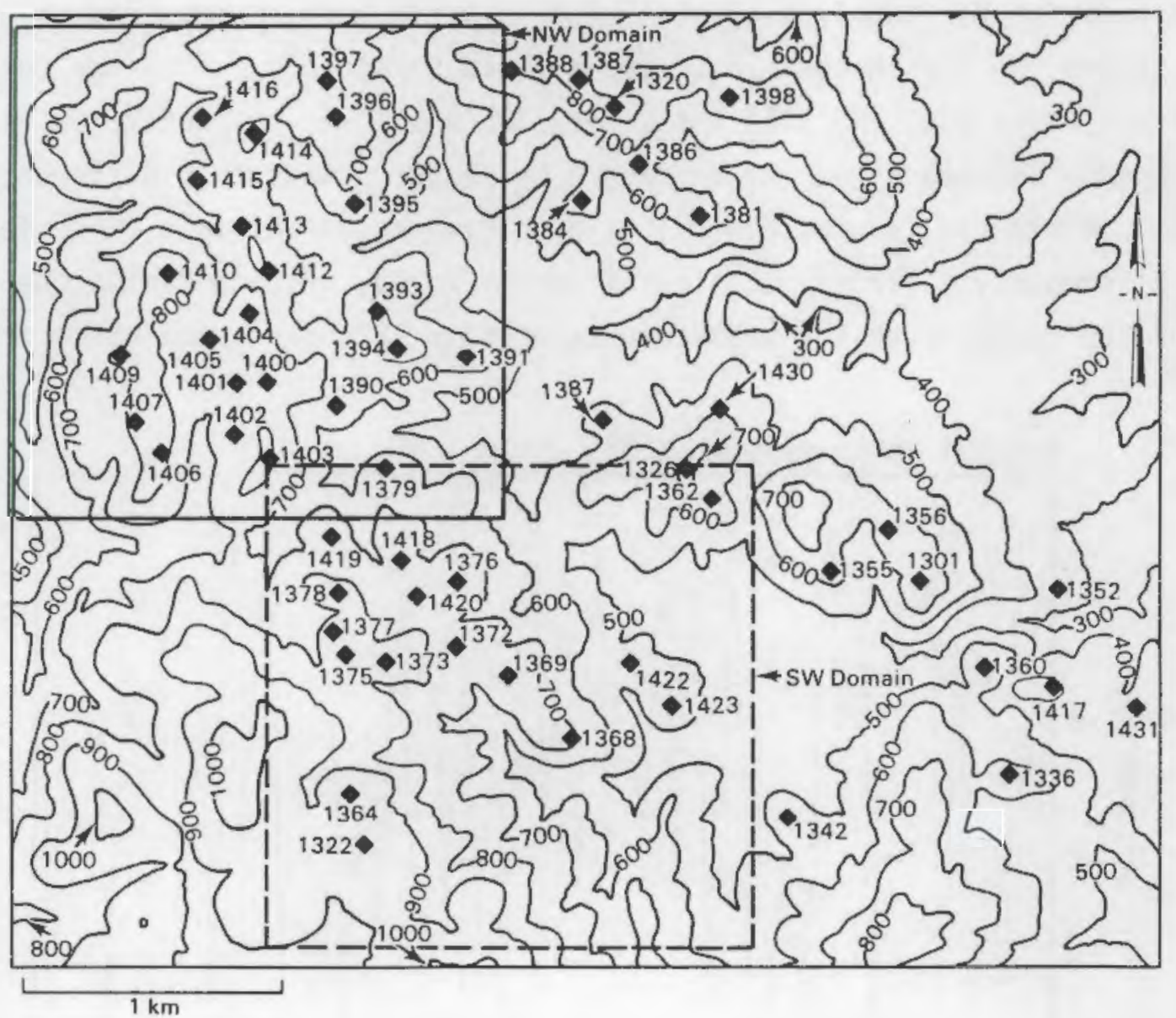

FIGURE 1. Terrain Contour Map with Wind Observation Sites Indicated by the Black Diamonds. The terrain contours are in feet, and the interval between contours is $100 \mathrm{ft}$. The NW modeling domain is delineated by the solid line; the dashed line indicates the SW domain. 
At each station wind speed observations were made for the entire month of August 1985 and reported as hourly averages. Figure 2 shows a time series plot of the wind data at Station 1301. The diurnal variation of the speed, characteristic of the Altamont Pass region, is clearly evident--higher speeds during the night and lower speeds during the day. All other stations exhibit this diurnal pattern.

Wind direction measurements were available from two stations, 1326 and 1394. Figure 3 shows the daily average wind direction plotted against day number. The daily average direction is the vector-resultant direction calculated from the 24 (hourly averaged) wind velocity vectors measured at each hour during the day in question. The average directions during the entire month are about $240^{\circ}$ and $225^{\circ}$ for sites 1326 and 1394 , respectively. The $15^{\circ}$ discrepancy between sites may be caused by sensor orientation differences or actual differences in wind direction, or a combination of both these factors. This discrepancy is fairly constant from day to day, except during the second day of the month, when the measurements at site 1326 indicated winds from $280^{\circ}$

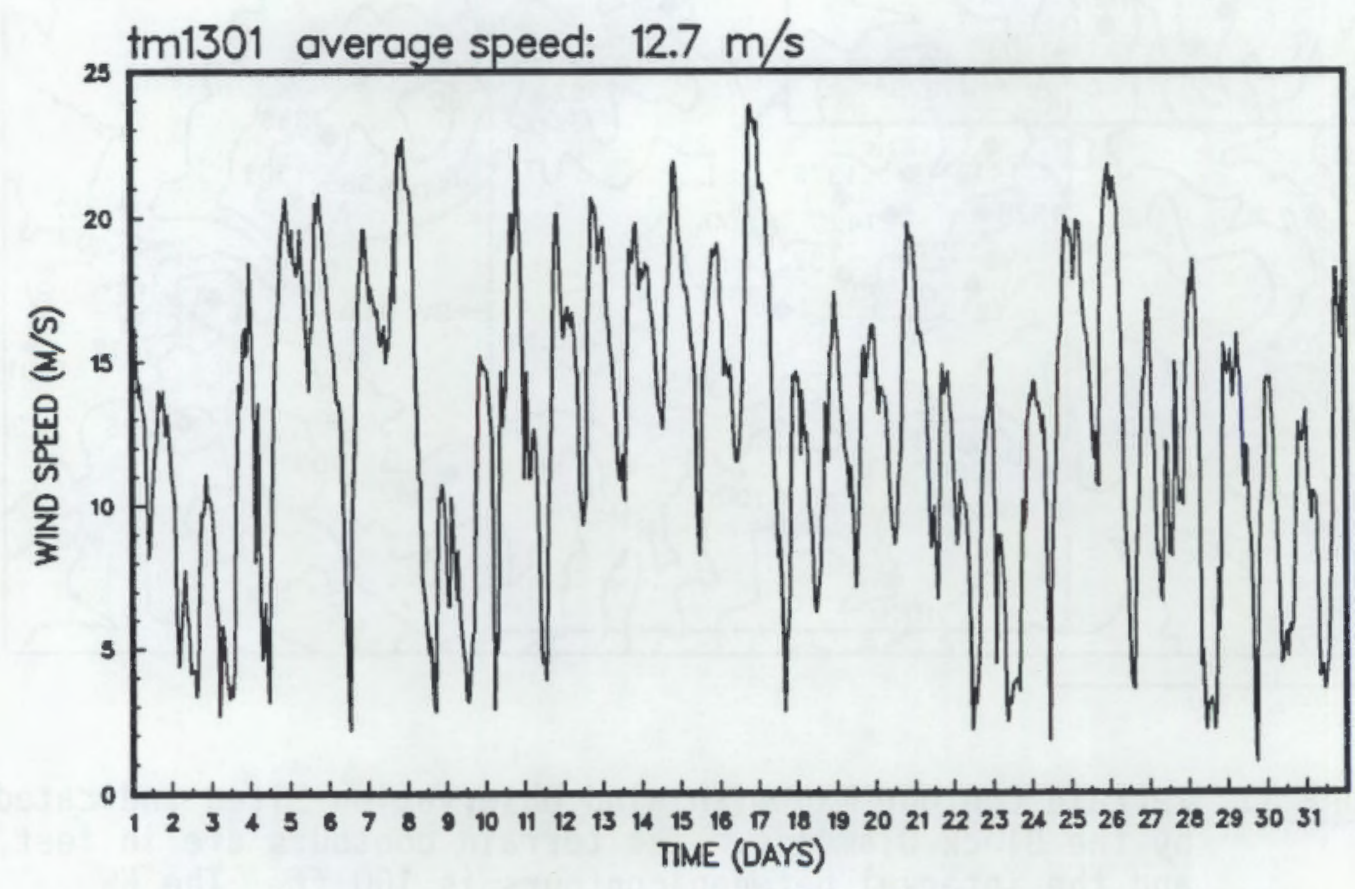

FIGURE 2. Time Series of the Hourly Averaged Wind Speeds for Wind Observation Site 1301 During August 1985 


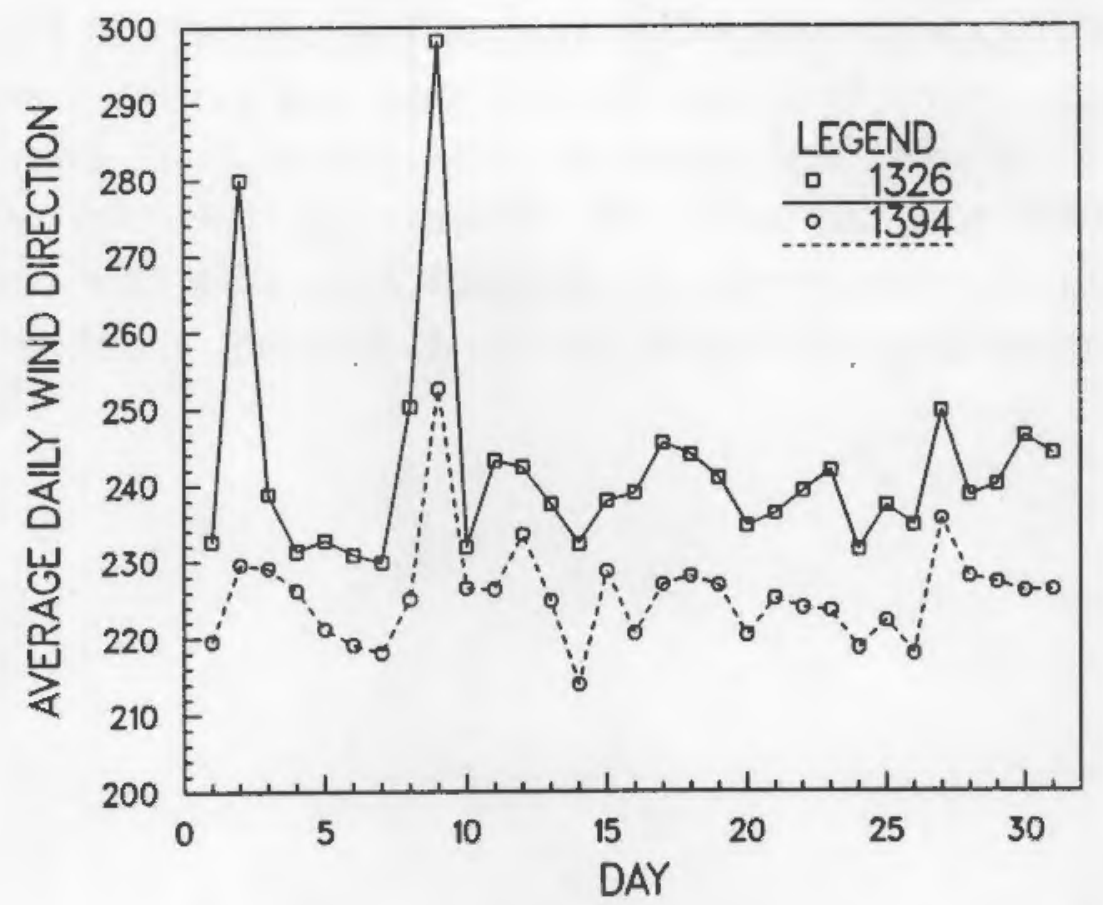

FIGURE 3. Averaged Daily Wind Directions for Stations 1326 and 1394

while the winds at site 1394 were measured from $230^{\circ}$. This event occurred during a period of low wind speeds (see Figure 2), when wind direction tends to be more variable from site to site.

of the 58 stations, 1 (1322) had obvious sensor problems as revealed by a spurious trend in the time series plot of the wind data. For 6 stations, a substantial fraction of the observations was missing. Two stations, 1320 and 1410, had only two and three missing observations, respectively. The remaining 49 stations had the full complement of 744 observations, and these data appeared to be error-free.

For the 2 stations with just a few hours of missing data, proxy data were substituted for these hours either by linear interpolation or by using wind data from a nearby station. Because at most only 3 observations were missing out of a possible 744 , the use of apparently reliable proxy data should not cause any significant error in the results presented in this report. When these two stations are included in the group that has a full 744 observations, there are then a total of 51 stations available for model verification. 
Table 1 lists wind observation information about all 58 stations. For the 51 stations with a full complement of data, the monthly average speed and the average gross power are tabulated. (The average gross power will be explained in the next section.) The average speed shows considerable variation over the site; it ranges from a low of about $8 \mathrm{~m} / \mathrm{s}$ to a high of about $13 \mathrm{~m} / \mathrm{s}$. Wind speed frequency distributions for the 51 stations are shown in Appendix $A$. 


\section{TABLE 1. Wind Observation Information}

\begin{tabular}{|c|c|c|c|}
\hline Station ID & $\begin{array}{c}\text { Average } \\
\text { Speed }(\mathrm{m} / \mathrm{s})\end{array}$ & $\begin{array}{l}\text { Average Gross } \\
\text { Power (kW) } \\
\end{array}$ & Comments \\
\hline 1301 & 12.7 & 138 & \\
\hline 1320 & 10.9 & 104 & 2 hours missing \\
\hline 1322 & & & sensor problems \\
\hline 1326 & 13.0 & 143 & \\
\hline 1336 & 11.6 & 118 & \\
\hline 1342 & 12.4 & 133 & \\
\hline 1352 & & & partial data \\
\hline 1355 & 11.9 & 125 & \\
\hline 1356 & & - & partial data \\
\hline 1360 & & $\therefore$ & partial data \\
\hline 1362 & 12.8 & 139 & \\
\hline 1364 & 10.1 & 86 & \\
\hline 1368 & 12.2 & 129 & \\
\hline $\begin{array}{l}1369 \\
1372\end{array}$ & $\begin{array}{l}12.5 \\
10.9\end{array}$ & $\begin{array}{l}133 \\
103\end{array}$ & \\
\hline 1373 & 10.3 & 89 & \\
\hline 1375 & 10.5 & 95 & \\
\hline 1376 & 12.0 & 125 & \\
\hline 1377 & 9.5 & 74 & \\
\hline 1378 & 10.7 & 99 & \\
\hline 1379 & 11.1 & 108 & \\
\hline 1381 & 11.1 & 108 & \\
\hline 1382 & 13.0 & 142 & \\
\hline 1384 & 10.7 & 99 & \\
\hline 1386 & & & partial data \\
\hline 1387 & 10.8 & 102 & \\
\hline 1388 & 9.6 & 76 & \\
\hline 1390 & 9.1 & 66 & \\
\hline 1391 & 11.2 & 109 & \\
\hline 1393 & 10.6 & 97 & \\
\hline 1394 & 11.7 & 119 & \\
\hline 1395 & 10.4 & 95 & \\
\hline 1396 & 10.7 & 100 & \\
\hline 1397 & 9.6 & 78 & \\
\hline 1398 & 10.3 & 91 & \\
\hline 1400 & 10.3 & 91 & \\
\hline 1401 & 8.7 & 57 & \\
\hline 1402 & 8.2 & 47 & \\
\hline 1403 & 10.4 & 91 & \\
\hline 1404 & 9.3 & 70 & \\
\hline 1405 & 9.0 & 64 & \\
\hline 1406 & 9.5 & 72 & \\
\hline 1407 & 8.3 & 49 & \\
\hline $\begin{array}{l}1409 \\
1410\end{array}$ & $\begin{array}{r}8.6 \\
10.0\end{array}$ & $\begin{array}{l}54 \\
84\end{array}$ & 3 hours missing \\
\hline 1412 & 9.1 & 66 & \\
\hline 1413 & 8.5 & 53 & \\
\hline 1414 & 8.5 & 52 & \\
\hline $\begin{array}{l}1415 \\
1416\end{array}$ & $\begin{array}{l}8.2 \\
8.3\end{array}$ & $\begin{array}{l}47 \\
50\end{array}$ & \\
\hline 1417 & 10.8 & 102 & \\
\hline 1418 & 10.4 & 94 & \\
\hline 1419 & 10.5 & 94 & \\
\hline 1420 & 10.8 & 101 & \\
\hline 1422 & 11.7 & 120 & \\
\hline 1423 & 11.9 & 123 & \\
\hline 1430 & - & - & partial data \\
\hline 1431 & - & - & partial data \\
\hline
\end{tabular}





\subsection{MODEL VERIFICATION METHODOLOGY}

The methodology for the flow model verification follows a number of steps. Briefly, these are:

- selection of the area to be modeled

- selection of the tuning and verification sites (to be defined in Section 3.2)

- calculation of the monthly average gross power at the tuning and verification sites

- data summarization

- comparison of the model results to the observations.

The application of these steps to the case at hand is explained below.

\subsection{SELECTION OF THE AREA TO BE MODELED}

The first step in the flow model verification is the selection of the area to be modeled; this area is termed the modeling domain. The modeling domain is represented in the model by terrain elevations at discrete model grid points. If the terrain is to be adequately resolved, then the horizontal distance between model grid points cannot exceed a certain limit. On the other hand, it is often desirable that the modeling domain be made as large as possible. Thus a trade-off often must be made between maximizing the size of the domain and minimizing the number of grid points, thereby conserving computer resources. In a previous study (Barnard, Wegley and Hiester 1987) a horizontal grid spacing of $50 \mathrm{~m}$ provided sufficient terrain resolution in the Altamont Pass area, and additionally, model operations did not consume extremely large amounts of computer time for a horizontal 40 by 40 grid (i.e.. 1600 horizontal grid points).

If the entire area as shown in Figure 1 were modeled using a grid spacing of $50 \mathrm{~m}$, then the number of horizontal grid points would exceed 1600 by a factor of 4 , and the computer time required for a single model run would be very large. Therefore two smaller modeling domains were selected for this study; these are depicted in Figure 1 . The domain in the northwest corner of 
the terrain, delineated by the solid line in the figure, is called the "NW" domain, and the domain in the south-central part of this terrain, delineated by the dashed line, is called the "SW" domain. (Note that the domains overlap somewhat.) Both domains are square and of identical size. In discrete form they are represented by a horizontal grid mesh consisting of 37 points in both the $x$ (east-west) and the $y$ (north-south) directions. The horizontal spacing between the grid points is $50 \mathrm{~m}$ so that the distance along any edge of these domains is $1.85 \mathrm{~km}$, and the area of each domain is about $3.4 \mathrm{~km}^{2}$.

\subsection{SELECTION OF THE TUNING AND VERIFICATION SITES}

The model requires as input wind observations taken at a number of sites over the area of interest. These sites are called tuning sites and they serve two purposes. First, they are used for model initialization. In Barnard, Wegley and Hiester (1987), only one of the tuning sites was used for model initialization. In the present study, all sites are used. This modification was found to give better modeling results. The second purpose for these sites is, as the name implies, for model tuning. The error between model-calculated winds and the observed winds at these sites forms a basis for gauging the model's performance. During the tuning process, the optimization procedure adjusts $\tau$ (and $\theta$ ) until this error is minimized--at this point $\tau$ and $\theta$ have assumed their optimum values. Once these are known, model calculations of the wind at locations away from the tuning sites should be much more accurate than winds derived using values of $\tau$ and $\theta$ that have been obtained by guesswork (unless one has the good fortune of guessing the optimum values!).

It is desirable that the number of tuning sites required to achieve good modeling results be as small as possible; unfortunately, this minimum number, which may depend on the area being modeled, has not yet been determined. Guidance as to an adequate number of stations can be obtained from Barnard, Wegley and Hiester (1987); in this study the model performed well when the tuning station density was from 1.5 to 2 stations per $\mathrm{km}^{2}$. The modeling domains considered here have an area of $3.4 \mathrm{~km}^{2}$; therefore, from 5 to 7 sites should be sufficient, and 6 tuning sites were selected for each domain. Table 2 lists these sites and their locations (in this table the tuning sites are indicated by a $T$ in column 4 ). The locations of the sites are measured in 
TABLE 2. Location of Tuning and Verification Sites for the NW and SW Modeling Domains

\begin{tabular}{|c|c|c|c|}
\hline $\begin{array}{c}\text { Station } \\
\text { Identification }\end{array}$ & $\underline{X(\mathrm{~km})}$ & $\underline{Y(\mathrm{~km})}$ & $\begin{array}{l}\text { Station } \\
\text { Type(a) } \\
\end{array}$ \\
\hline \multicolumn{4}{|c|}{ NW DOMAIN } \\
\hline $\begin{array}{l}1394 \\
1410 \\
1409 \\
1407 \\
1406 \\
1416 \\
1415 \\
1405 \\
1414 \\
1413 \\
1412 \\
1404 \\
1401 \\
1400 \\
1402 \\
1403 \\
1397 \\
1396 \\
1395 \\
1393 \\
1390 \\
1379 \\
1391\end{array}$ & $\begin{array}{l}1.44 \\
0.58 \\
0.40 \\
0.45 \\
0.56 \\
0.72 \\
0.69 \\
0.73 \\
0.89 \\
0.85 \\
0.95 \\
0.88 \\
0.82 \\
0.95 \\
0.82 \\
0.96 \\
1.17 \\
1.22 \\
1.28 \\
1.36 \\
1.21 \\
1.40 \\
1.69\end{array}$ & $\begin{array}{l}0.66 \\
0.93 \\
0.63 \\
0.39 \\
0.27 \\
1.50 \\
1.28 \\
0.69 \\
1.44 \\
1.11 \\
0.94 \\
0.79 \\
0.52 \\
0.52 \\
0.33 \\
0.24 \\
1.65 \\
1.51 \\
1.18 \\
0.79 \\
0.44 \\
0.20 \\
0.63\end{array}$ & $\begin{array}{l}T \\
V \\
T \\
V \\
V \\
T \\
V \\
V \\
V \\
V \\
V \\
V \\
V \\
V \\
T \\
T \\
V \\
V \\
V \\
T \\
V \\
V \\
T \\
T \\
\text { V }\end{array}$ \\
\hline
\end{tabular}

SW DOMAIN

$\begin{array}{llll}1375 & 0.32 & 1.11 & \mathrm{~T} \\ 1362 & 1.71 & 1.68 & \mathrm{~T} \\ 1419 & 0.27 & 1.55 & \mathrm{~T} \\ 1418 & 0.52 & 1.46 & \mathrm{~V} \\ 1376 & 0.73 & 1.40 & \mathrm{~V} \\ 1378 & 0.28 & 1.37 & \mathrm{~V} \\ 1420 & 0.58 & 1.35 & \mathrm{~V} \\ 1377 & 0.27 & 1.20 & \mathrm{~V} \\ 1373 & 0.48 & 1.10 & \mathrm{~V} \\ 1372 & 0.73 & 1.14 & \mathrm{~V} \\ 1369 & 0.93 & 1.03 & \mathrm{~T} \\ 1422 & 1.40 & 1.08 & \mathrm{~V} \\ 1423 & 1.55 & 0.92 & \mathrm{~V} \\ 1368 & 1.17 & 0.78 & \mathrm{~T} \\ 1364 & 0.34 & 0.59 & \mathrm{~T}\end{array}$

(a) $\quad T=$ Tuning Site, $V=$ Verification Site. 
kilometers from the lower left-hand corner of the modeling domain in which the station resides. Figure 4 depicts the terrain of the two modeling domains; in this figure the tuning sites are shown as filled-in circles.

The tuning sites were selected in a manner that was not entirely arbitrary. Because the wind speed varies significantly over the modeling domains considered here, the tuning sites should be selected to capture this variation, so that the model initialization will be made with a reasonably good estimate of the actual wind flow. Obviously, this will not be accomplished if all the tuning sites are clustered closely together, so a requirement for locating these sites is that they be geographically distributed in accordance with some subjective appraisal of the actual wind speed variation. Placement of the tuning sites in areas of both topographically enhanced and diminished wind speed not only aids in model initialization, it also increases the sensitivity of the error between the modeled and observed winds to $\tau$ and $\theta$, thereby facilitating the tuning process.

There are 23 observation stations in the NW domain and 15 in the SW domain. Of these stations, 6 in each domain are designated as tuning sites, and since the winds from these sites are used for model input, they cannot be used to assess the performance of the model. This task falls to the remaining stations, of which there are 17 and 9 in the NW and SW domains, respectively. These stations are termed verification stations, and they are also listed in Table 2 (they are indicated by a $V$ in column 4 ). The filled-in squares in Figure 4 mark the locations of these sites.

The wind data at the verification sites can be used directly for model verification. That is, calculated winds can be compared to observed winds, and a figure of merit [for example, the root mean square error (RSME)], can be used to quantitatively gauge the model's performance. Another method of using the wind data consists of calculating some quantity from the observed and model-derived winds--such as the average gross power--and then comparing observed and calculated values of this quantity. In this report, model performance will be assessed by using both average gross powers and average wind speeds. (For this particular data set, both approaches are essentially equivalent, as will be shown later.) 

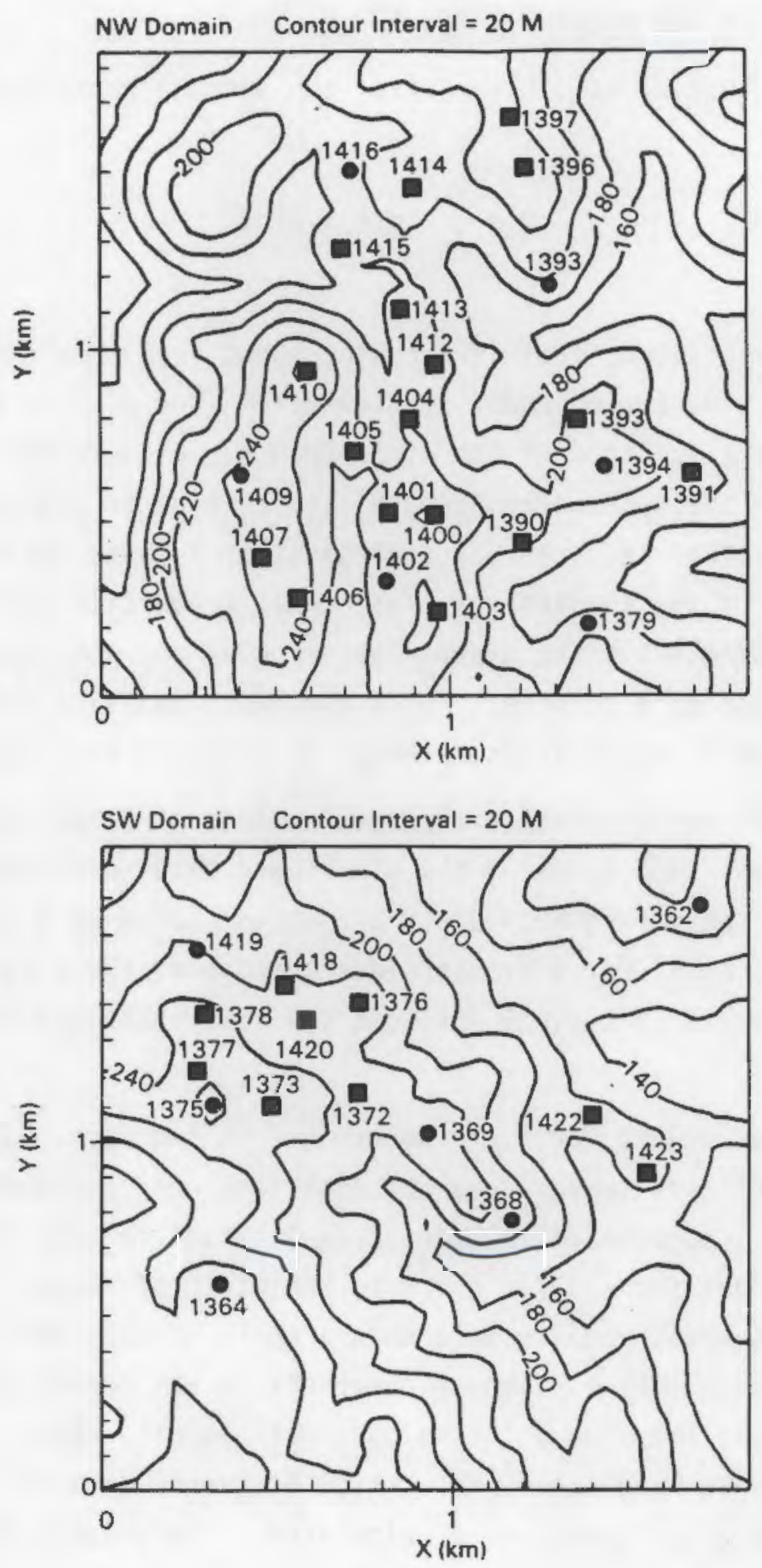

FIGURE 4. The NW and SW Modeling Domains. The terrain contour interval is $20 \mathrm{~m}$. The tuning and verification sites are indicated by the circles and squares, respectively. 


\subsection{CALCULATION OF THE AVERAGE GROSS POWER}

For a given turbine at a given site, the average gross power, P, is:

$$
P=\int_{0}^{\infty} p(s) f(s) d s
$$

where $s$ is the wind speed, $f(s)$ is the wind speed frequency distribution at the site for the time period under consideration, and $p(s)$ is the power output of the turbine as a function of the wind speed $s$. Because the gross power does not consider the dynamic response of the turbine to wind speed variations or the myriad of other factors that contribute to turbine performance, it is only an estimate of the turbine's average power production over the time period in question. Consequently the average gross power may not represent well the actual power output of a turbine. For a specified modeling domain, however, relative values of $P$ should indicate areas of enhanced wind energy potential.

For the model verification, "observed" values of $\mathrm{P}$ can be determined for the month of August 1985 by using the wind speed data described in Section 2 to find the wind speed frequency distribution and assuming a power-versusspeed curve [i.e, $p(s)$ ] for a hypothetical turbine at the site. This curve is shown in Figure 5 ; it is typical for some turbines installed in the Altamont Pass area.

Model-derived values for $P$ are determined in two ways. The first of these makes use of wind speed frequency distributions obtained from modelcalculated winds. Because of computer time limitations, it is not possible to operate the model for all 744 hours in the month of August. (Model runs for all 744 hours would require more than a month of computer time on a VAX 11/780!) Thus a subset of these observations was found that represented as well as possible the flow patterns during the month. Model runs using this subset provided wind speeds from which frequency distributions were determined and average gross powers were calculated. The selection of this subset is discussed in the next section.

The second method involves operating the model once using monthly average speeds as input. Presumably, the calculated wind field is then an estimate 


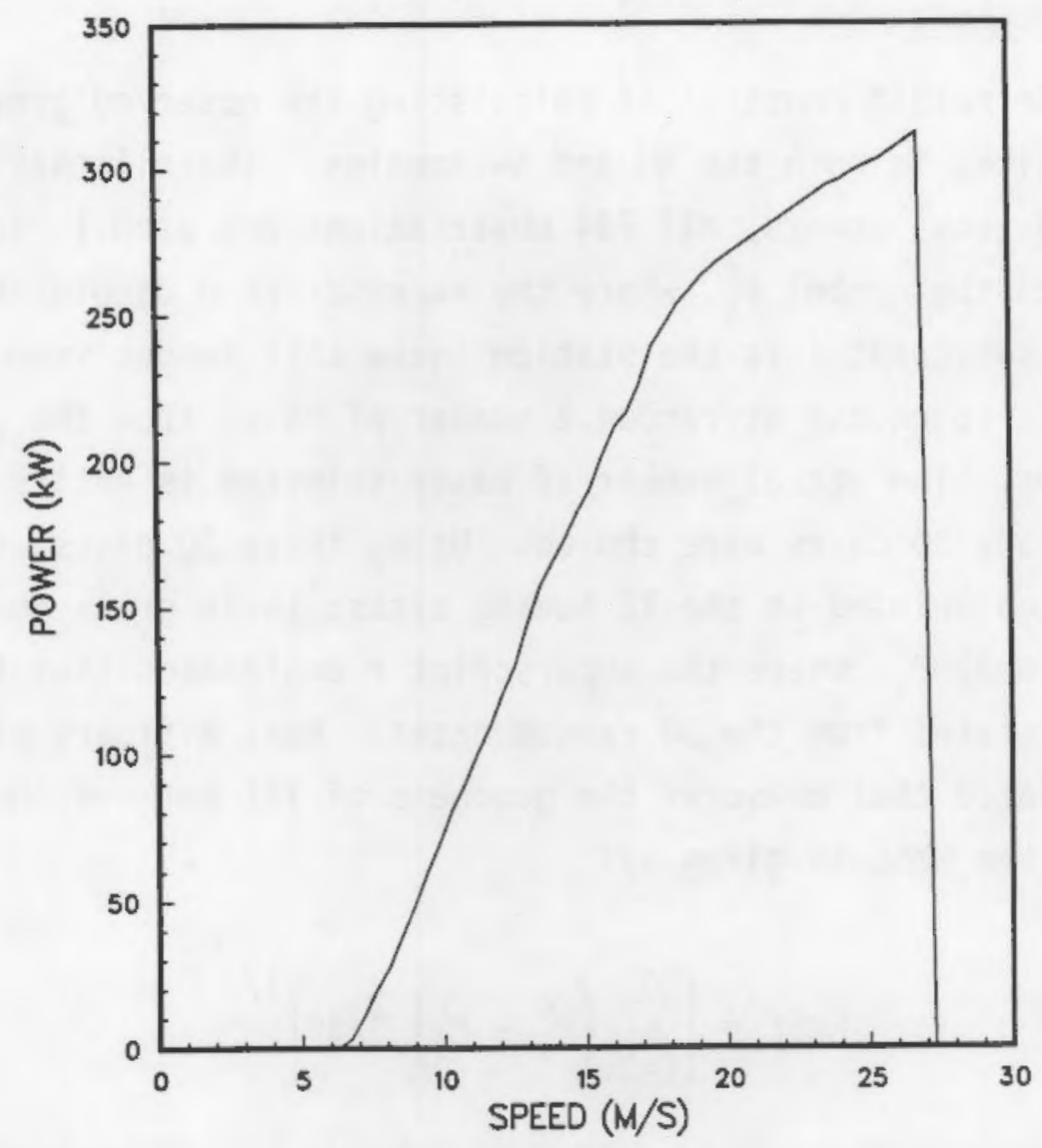

FIGURE 5. A Turbine Power-Versus-Speed Curve Used to Calculate Observed Average Gross Powers

of the mean monthly speed over the modeling domain in question. Next an empirical relationship between the mean monthly speed and gross power ( $P$ ) is derived; from this relationship and the calculated speeds, $P$ can be determined. This technique is also discussed in the next section.

\subsection{DATA SUMMARIZATION}

The selection of the subset with which to operate the model is a process referred to here as "data summarization." There are many possible methods of data summarization: principal components analysis (Hardy and Walton 1978), the use of mean data, and so-called random methods. This study will use both mean data and a random method. The random method is discussed first. 


\subsubsection{Random Methods}

This simple method consists of calculating the observed gross power at the 12 tuning sites in both the NW and SW domains. (Recall that when calculating observed gross powers, all 744 observations are used.) These gross powers are given the symbol $P_{i}^{0}$, where the superscript 0 denotes observed gross powers and the subscript $i$ is the station index that ranges from 1 to 12 . The next step is to choose at random a number of cases from the possible 744 hourly cases. The actual number of cases selected is entirely arbitrary, and for this study 30 cases were chosen. Using these 30 cases, the average gross power is calculated at the 12 tuning sites; these gross powers are assigned the symbol $P_{i}^{r}$, where the superscript $r$ designates that these gross powers are calculated from the 30 random cases. Next a figure of merit, the RMSE, is calculated that measures the goodness of fit between the $P_{i}^{r}$ and the $P_{i}^{0}$; explicitly the RMSE is given by:

$$
\text { RMSE }=\left[\sum_{i=1}^{30}\left(P_{i}^{0}-P_{i}^{r}\right)^{2 / 30}\right]^{1 / 2}
$$

Each set of 30 cases is associated with a RMSE. Sets of 30 random cases can be repeatedly selected--for this study 50 sets were picked--and the set with the lowest RMSE can be taken as that subset of wind observations that represents the power-producing winds during August.

The time (day and hour) and average speed of the 12 tuning sites is displayed in Table 3 for the set of 30 cases with the lowest RMSE. Note that one case (day 25, hour 23) was selected twice. An examination of the average speeds reveals that a majority of cases have mean speeds in excess of $10 \mathrm{~m} / \mathrm{s}$, and only a few cases have average speeds less than $5 \mathrm{~m} / \mathrm{s}$. It therefore seems reasonable that these cases represent the actual wind patterns during the month of August when the winds are generally very strong.

Further information about the characteristics of the 30 cases listed in Table 3 can be gained by comparing two frequency distributions. The first of these is a distribution of the average speed at the 12 tuning sites, where the average is over the 30 cases (i.e., the fourth column of Table 3 ), while the second is a distribution of the average speeds at the same sites; however, 
TABLE 3. Subset of 30 Cases Used to Represent the Flow During August 1985

\begin{tabular}{|c|c|c|c|}
\hline Case & Day & Hour & $\begin{array}{c}\text { Average Speed of } \\
12 \text { Tuning Sites } \\
(\mathrm{m} / \mathrm{s})\end{array}$ \\
\hline 1 & 11 & 5 & 10.3 \\
\hline 2 & 19 & 23 & 12.4 \\
\hline 3 & 12 & 17 & 12.4 \\
\hline 4 & 18 & 10 & 6.9 \\
\hline 5 & 4 & 23 & 14.2 \\
\hline 6 & 21 & 17 & 10.0 \\
\hline 7 & 1 & 10 & 8.2 \\
\hline 8 & 8 & 24 & 7.8 \\
\hline 9 & 30 & 21 & 9.8 \\
\hline 10 & 10 & 16 & 13.5 \\
\hline 11 & 31 & 13 & 3.6 \\
\hline 12 & 25 & 23 & 14.4 \\
\hline 13 & 15 & 19 & 15.0 \\
\hline 14 & 19 & 21 & 13.2 \\
\hline 15 & 15 & 20 & 16.0 \\
\hline 16 & 28 & 19 & 5.4 \\
\hline 17 & 23 & 13 & 3.2 \\
\hline 18 & 15 & 24 & 16.4 \\
\hline 19 & 22 & 20 & 9.4 \\
\hline 20 & 31 & 20 & 13.1 \\
\hline 21 & 20 & 13 & 6.9 \\
\hline 22 & 7 & 3 & 15.9 \\
\hline 23 & 16 & 9 & 12.4 \\
\hline 24 & 21 & 13 & 7.4 \\
\hline 25 & 9 & 8 & 7.9 \\
\hline 26 & 24 & 11 & 4.6 \\
\hline 27 & 25 & 23 & 14.4 \\
\hline 28 & 16 & 10 & 10.5 \\
\hline 29 & 25 & 11 & 12.7 \\
\hline 30 & 4 & 9 & 8.3 \\
\hline
\end{tabular}

Note that cases 12 and 27 are identical.

now the average is over all 744 hours in the month of August. This comparison reveals to what extent the 30 -case distribution is similar to the actual distribution. Figure 6 illustrates this comparison. In the top plot, both frequency distributions have been plotted, where the speeds have been placed in bins of width $2 \mathrm{~m} / \mathrm{s}$. (But the first bin extends from 0 to $1 \mathrm{~m} / \mathrm{s}$, and only has a width of $1 \mathrm{~m} / \mathrm{s}$. The limits on the other bins are $1-3,3-5,5-7, \ldots \mathrm{m} / \mathrm{s}$.) The black dot and open square indicate the frequency of winds in a particular 
(a) DATA IN BINS OF WIDTH $2 \mathrm{M} / \mathrm{S}$

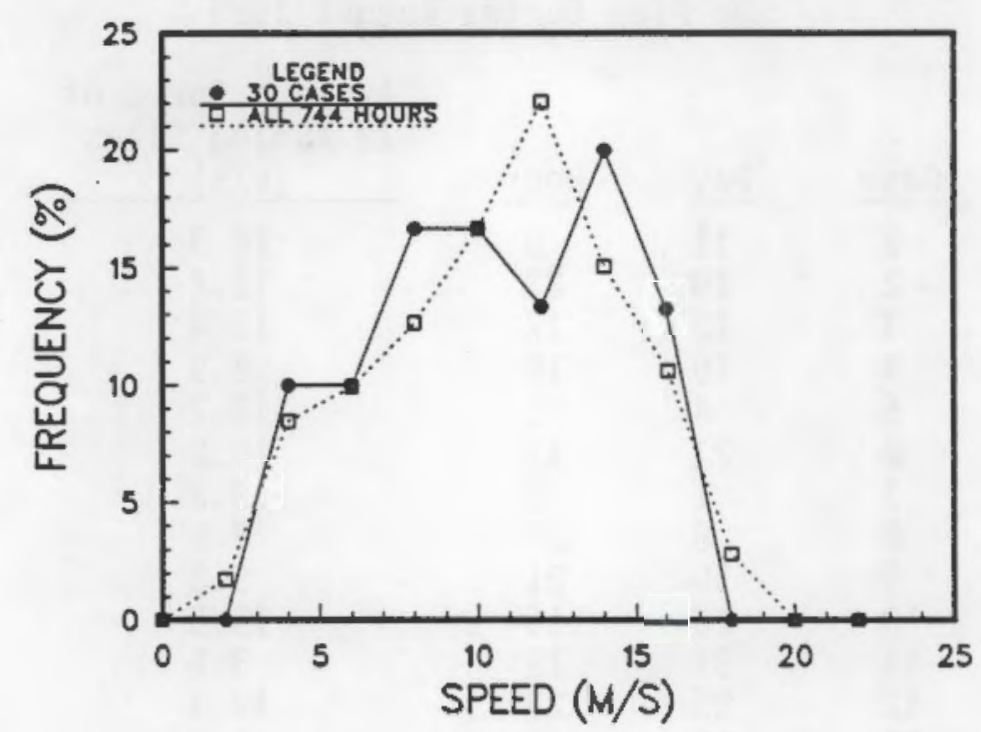

(b) SMOOTHED DISTRIBUTIONS

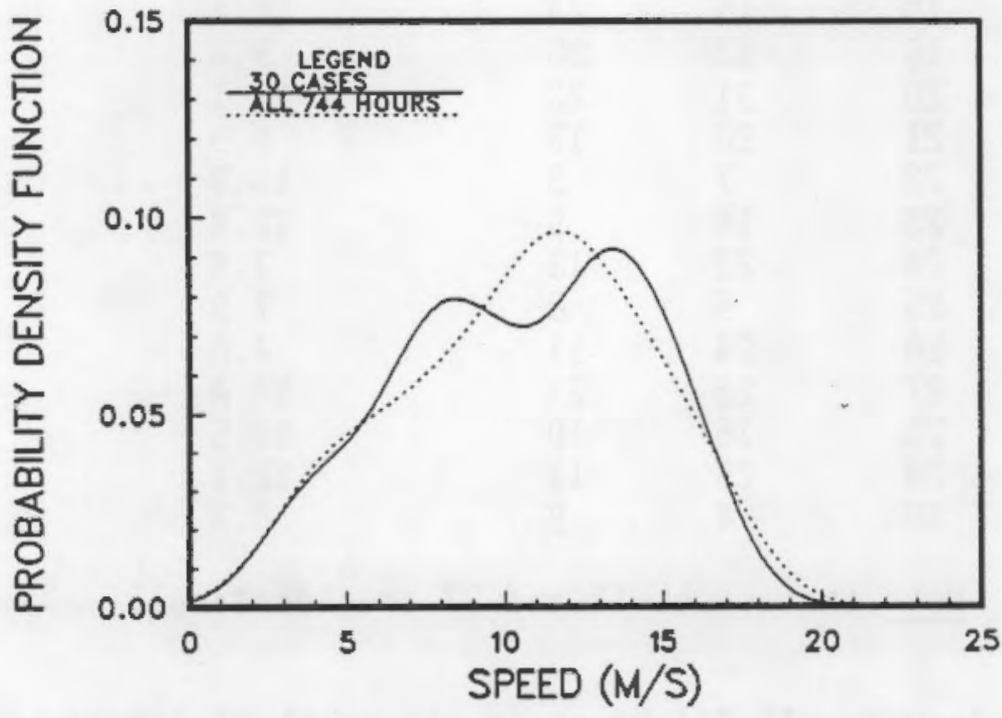

FIGURE 6. Discrete (a) and Smoothed (b) Frequency Distributions for the Average Speed at the 12 Tuning Sites. The distributions are formed from either (1) only the 30 cases listed in Table $3(-)$ or (2) all 744 hours in the month $(\cdots)$. These plots show how well the 30 cases represent the winds during the entire month. 
bin for the 30-case and "744-hour" distribution, respectively. (The lines connecting these symbols merely facilitate the comparison of the distributions.) The distributions appear roughly comparable; however the 30-case distribution exhibits a double-humped shape that is not observed in the 744-hour distribution. This feature would diminish as more than 30 cases are added to the subset used to represent the entire month.

The 30-case and 744-hour distributions are both discrete distributions, with non-zero frequencies occurring only at discrete values of the wind speed. The form of these distributions is dependent upon the width of the bins used to make them. Another way of portraying these distributions is to form continuous representations by convolving the unbinned wind data with a Gaussian function. Mathematically, we have

$$
c(s)=\frac{1}{744} \sum_{i=1}^{744} \frac{1}{\sqrt{2 \pi} \sigma} e^{-\frac{\left(s-s_{i}^{\prime}\right)^{2}}{2 \sigma^{2}}}
$$

where $c(s)$ is the continuous representation of a distribution, and $s_{i}^{\prime}$ is the ith speed in the set of 744 speeds. The continuous distribution, $c(s)$, can be considered to be a probability density function. The standard deviation of the Gaussian function is specified by $\sigma$, which is taken to be $1.5 \mathrm{~m} / \mathrm{s}$. The 30-case and 774-hour continuous distributions are shown in the bottom plot of Figure 6 . The nature of the two distributions are shown somewhat more clearly in continuous form, and they are actually quite similar, except for the doublehumped behavior persists even in the continuous representations.

The validity of the random method was investigated by calculating the observed gross powers at the verification sites (using all 744 observations at a given site) and then quantitatively comparing these powers to the calculated powers derived from the subset of 30 random cases. As was done for the tuning sites, the goodness of fit between the observed average gross powers and average gross powers (calculated from the 30 cases) was again measured by a RMSE. A RMSE was calculated for all 50 sets considered above. If the method 
described above has validity, then there should be a strong correlation between the RMSE of the tuning sites and the RMSE of the verification sites. A strong correlation implies that when the 30 cases accurately portray the powerproducing winds at the tuning sites, they also accurately represent the powerproducing flow at places away from the tuning sites. Figure 7 plots the RMSE associated with the verification sites versus the RMSE identified with the tuning sites. As is clearly evident, the correlation between these quantities is quite strong, and in fact, $r^{2}$ is 0.98 . Thus, the method appears to work quite well.

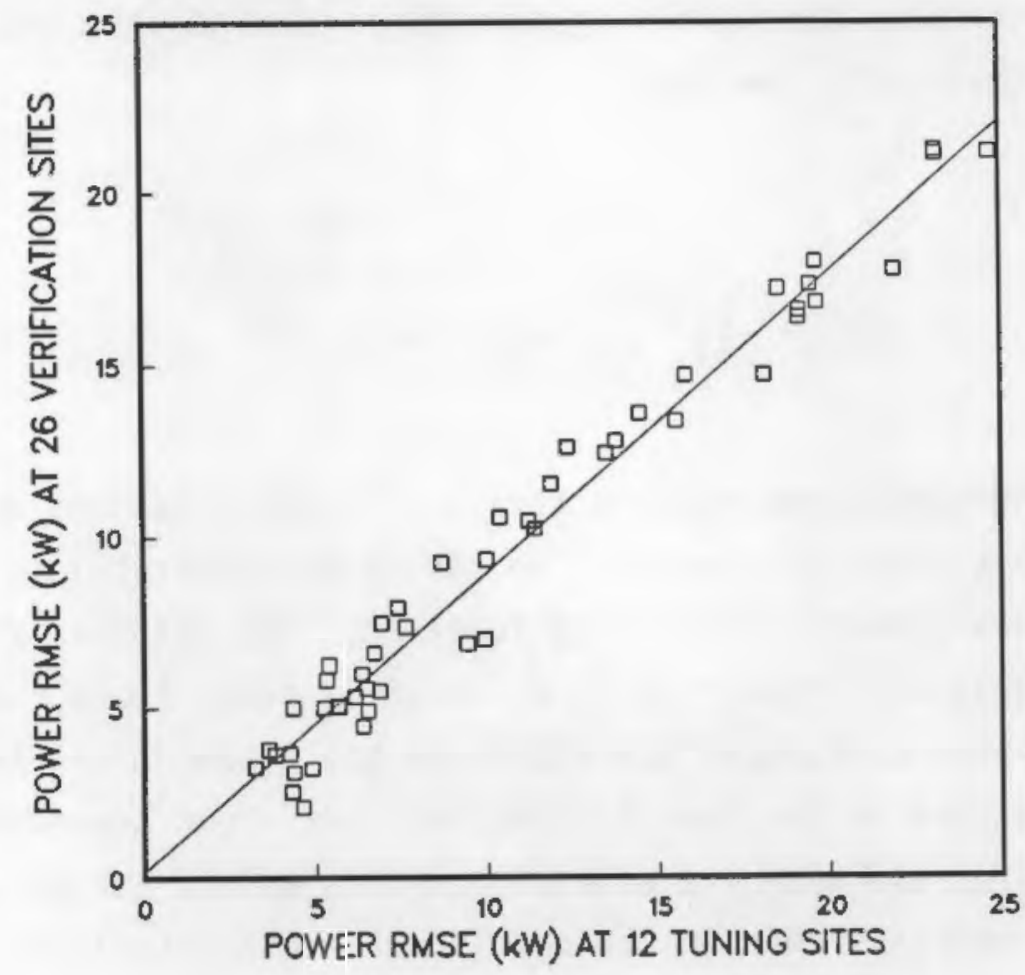

FIGURE 7. Scatter Plot of Power RMSE of the Verification Sites Versus the Power RMSE of the Tuning Sites for the 50 Sets of 30 Hourly Cases Selected at Random. Note that when the RMSE of the tuning sites is large so is the RMSE of the verification sites. This shows that when the 30 cases accurately represent the power-producing winds at the tuning sites, they also represent well these winds away from the tuning sites. 


\subsubsection{Using Mean Data}

Running the model using mean data presents no untoward difficulties. In this study the model will be run once in each domain using mean monthly winds at the tuning sites. The tuning sites are those indicated in Table 2, and the mean monthly speeds for each of these sites are contained in Table 1.

If observed and predicted gross powers are to be compared, it is necessary to derive an empirical relationship between mean monthly wind speed and mean monthly gross power, so that predicted monthly speeds can be converted to predicted gross power. Derivation of this relationship is quite easy. For the 51 stations listed in Table 2, Figure 8 shows the monthly mean gross power plotted versus mean monthly speed. Over the range of speeds considered here, the relationship between these quantities is very close to linear, although the linearity begins to break down at about $13 \mathrm{~m} / \mathrm{s}$. This behavior is a direct consequence of the linearity of the power-versus-speed curve (Figure 5) between the speeds of about $7 \mathrm{~m} / \mathrm{s}$ and $18 \mathrm{~m} / \mathrm{s}$, and the fact that the fraction of a site's wind speed distribution that falls within this speed range is relatively constant from site to site. This fraction begins to decrease for the sites with the higher speeds, and consequently the linear relationship begins to deteriorate.

A line of regression fit to the data graphed in Figure 8 gives the desired empirical relationship between mean monthly speed and mean monthly gross power. This relationship is: [mean monthly gross power $(\mathrm{kW})$ ] $=20.33^{\star}$ [mean monthly speed $(\mathrm{m} / \mathrm{s})$ ] - 119.34. In practice, the wind farm developer would only have speeds available from the 12 tuning sites with which to develop this relationship; however, the relationship derived using only 12 sites is essentially identical to the one given above.

Because of the linear connection between mean speeds and gross powers, the mean power is (aside from a constant factor) directly proportional to the mean speed. Hence, for this particular situation, prediction of the mean speed is equivalent to prediction of the gross power, and prediction of the gross power becomes redundant. This would not necessarily hold for different turbine performance curves or different wind speed frequency distributions. In this study, the calculation of the gross powers will be carried through so as to provide information as to how the predicted and gross power actually compare. 


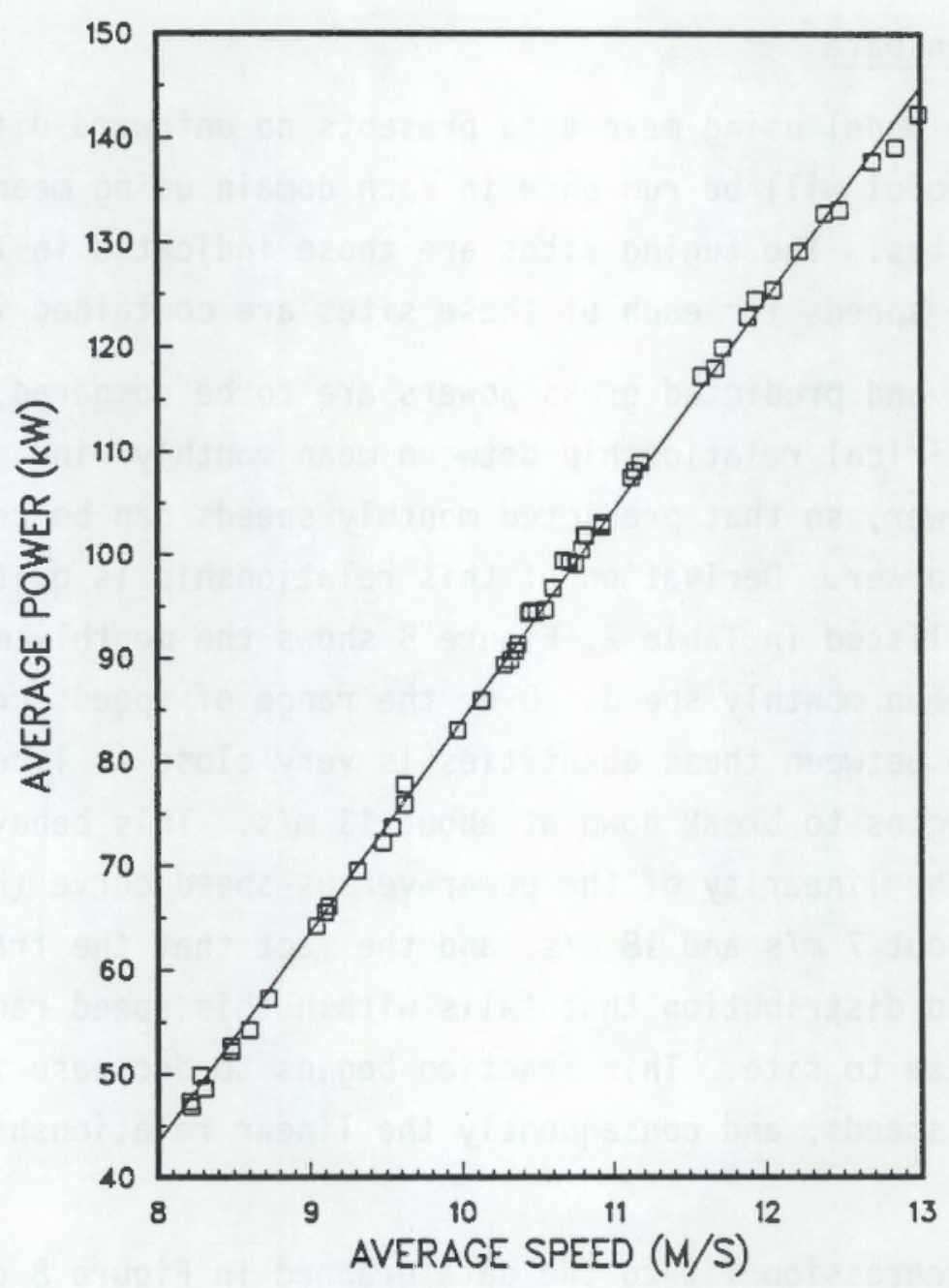

FIGURE 8. Monthly Averaged Power Plotted Versus Monthly Averaged Speed for the 51 Stations with a Full 744 Hours of Data; These Stations Comprise the Bulk of Table 1. The solid line is a line of regression fit to these data.

\subsection{COMPARISON OF THE MODEL RESULTS TO THE OBSERVATIONS}

For both domains, NW and SW, the model was operated using the 30 cases listed in Table 3 and mean monthly speeds. Model performance was assessed qualitatively though the use of scatter plots that plot predicted versus observed average wind speeds (and also gross powers) at the verification and tuning sites. Quantitative assessment was provided by the RMSE between these same quantities. Studies by Willmott (1984) and Willmott et al. (1985) have emphasized the usefulness of the scatter plot and the RMSE as effective means of displaying model performance. 


\subsection{VERIFICATION OF SPEEDS ANO GROSS POWERS}

\subsection{VERIFICATION USING THE 30 CASES}

The model was operated for the 30 cases listed in Table 3 . The results of the model tuning process for these cases and for each modeling domain are displayed in Table 4. This table consists of the optimum values of $\tau$ and $\theta$, the wind speed ratio RMSE at the tuning and verification sites (termed the tuning and verification RMSE, respectively), the CPU time (in minutes) required for model execution, and finally, the average speed of the 6 tuning sites in the specified domain. The wind speed ratios, from which the wind speed ratio RMSEs are calculated, are formed by dividing the observed (or model-derived) wind speed by the wind speed at a reference site. For these calculations, the reference sites are 1394 in the NW domain and 1375 in the SW domain. [Barnard, Wegley and Hiester (1987) discusses wind speed ratios and their role in evaluating model performance.]

The verification RMSE, which is the RMSE between observed and calculated wind speed ratios at the verification sites, is an important measure of model performance. For many cases the verification RMSE is less than 0.10 , indicating good model performance. The cases with large verification RMSEs $(>0.2)$ are associated with low wind speeds that are frequently below the turbine's cut-in speed (about $7 \mathrm{~m} / \mathrm{s}$ ).

To compare average observed and calculated winds at the verification sites the model-derived winds are obtained at each verification site by averaging the calculated wind speeds over the 30 cases. Average observed winds are monthly averages obtained from the full complement of 744 hourly averaged wind speeds at each verification site. The observed and calculated winds for the two modeling domains are shown in Table 5; scatter plots that plot the modeled speed versus the observed speed are displayed in Figure 9. In this figure, the verification sites are indicated by the open squares, and the tuning sites are shown by the open circles. The tuning and verification RMSEs are indicated over each plot [i.e., RMSE ( $T$ ) and RMSE (V)]; the verification RMSEs are $0.46 \mathrm{~m} / \mathrm{s}$ and $0.54 \mathrm{~m} / \mathrm{s}$ for the $\mathrm{NW}$ and $S W$ domains, respectively. $A$ 
TABLE 4. Summary of Modeling Results for the 30 Cases. The tuning and verification RMSEs are wind speed ratio RMSEs. The speed in column 10 is the average over the 6 tuning sites of the domain in question.

\begin{tabular}{|c|c|c|c|c|c|c|c|c|c|}
\hline Case & Day & Hour & Doma in & $T$ & $\theta$ & $\begin{array}{l}\text { Tuning } \\
\text { RMSE } \\
\end{array}$ & $\begin{array}{c}\text { Verification } \\
\text { RMSE }\end{array}$ & $\begin{array}{c}\text { CPU } \\
\text { (min) }\end{array}$ & $\begin{array}{l}\text { Speed } \\
(\mathrm{m} / \mathrm{s})\end{array}$ \\
\hline \multirow[t]{2}{*}{1} & 11 & 5 & NW & -0.063 & 228 & 0.072 & 0.066 & 90 & 9.2 \\
\hline & & & SH & 1.240 & 213 & 0.089 & 0.077 & 89 & 11.4 \\
\hline \multirow[t]{2}{*}{2} & 19 & 23 & MH & -0.395 & 225 & 0.047 & 0.044 & 60 & 11.5 \\
\hline & & & SW & 1.390 & 207 & 0.095 & 0.063 & 125 & 13.3 \\
\hline \multirow[t]{2}{*}{3} & 12 & 17 & NH & 1.300 & 175 & 0.044 & 0.099 & 174 & 10.8 \\
\hline & & & SH & 1.100 & 185 & 0.036 & 0.061 & 155 & 14.0 \\
\hline \multirow[t]{2}{*}{4} & 18 & 10 & NH & -0.139 & 240 & 0.081 & 0.118 & 106 & 6.4 \\
\hline & & & SH & 1.990 & 155 & 0.028 & 0.129 & 195 & 7.4 \\
\hline \multirow[t]{2}{*}{5} & 4 & 23 & NH & 1.930 & 168 & 0.086 & 0.121 & 190 & 12.9 \\
\hline & & & SH & 0.960 & 183 & 0.038 & 0.077 & 167 & 15.5 \\
\hline \multirow[t]{2}{*}{6} & 21 & 17 & $\mathrm{NH}$ & 0.931 & 198 & 0.035 & 0.152 & 114 & 8.8 \\
\hline & & & SH & 1.170 & 189 & 0.032 & 0.069 & 149 & 11.2 \\
\hline \multirow[t]{2}{*}{7} & 1 & 10 & NH & -0.247 & 235 & 0.075 & 0.093 & 91 & 7.8 \\
\hline & & & SW & 1.990 & 180 & 0.025 & 0.070 & 146 & 8.5 \\
\hline \multirow[t]{2}{*}{8} & 8 & 24 & NH & 1.970 & 178 & 0.103 & 0.110 & 163 & 7.8 \\
\hline & & & SW & 1.080 & 151 & 0.039 & 0.063 & 242 & 8.5 \\
\hline \multirow[t]{2}{*}{9} & 30 & 21 & NH & 0.419 & 190 & 0.025 & 0.068 & 137 & 8.9 \\
\hline & & & SH & 1.840 & 173 & 0.044 & 0.084 & 172 & 10.8 \\
\hline \multirow[t]{2}{*}{10} & 10 & 16 & NH & 1.140 & 185 & 0.027 & 0.102 & 150 & 12.3 \\
\hline & & & SH & 0.390 & 221 & 0.042 & 0.075 & 62 & 14.7 \\
\hline \multirow[t]{2}{*}{11} & 31 & 13 & NH & -0.194 & 215 & 0.037 & 0.109 & 67 & 3.4 \\
\hline & & & SH & 0.470 & 175 & 0.035 & 0.074 & 158 & 3.7 \\
\hline \multirow[t]{2}{*}{12} & 25 & 23 & NH & 1.250 & 175 & 0.056 & 0.068 & 180 & 12.4 \\
\hline & & & SH & 0.670 & 172 & 0.041 & 0.082 & 213 & 16.5 \\
\hline \multirow{2}{*}{13} & 15 & 19 & NW & 1.060 & 175 & 0.034 & 0.070 & 180 & 13.7 \\
\hline & & & SH & 1.350 & 172 & 0.034 & 0.094 & 151 & 16.3 \\
\hline 14 & 19 & 21 & NW & 0.389 & 190 & 0.035 & 0.069 & 136 & 12.0 \\
\hline & & & SW & 1.680 & 167 & 0.004 & 0.057 & 222 & 14.4 \\
\hline 15 & 15 & 20 & $\mathrm{NH}$ & 1.140 & 173 & 0.038 & 0.084 & 195 & 14.3 \\
\hline & & & SH & 1.720 & 169 & 0.021 & 0.056 & 207 & 17.6 \\
\hline 16 & 28 & 19 & NH & 0.224 & 190 & 0.028 & 0.130 & 121 & 4.4 \\
\hline & & & SH & -0.840 & 237 & 0.029 & 0.301 & 107 & 6.5 \\
\hline 17 & 23 & 13 & NH & -0.102 & 190 & 0.033 & 0.089 & 128 & 3.1 \\
\hline & & & SH & -0.580 & 230 & 0.021 & 0.213 & 70 & 3.3 \\
\hline 18 & 15 & 24 & $\mathrm{NH}$ & 1.470 & 170 & 0.049 & 0.076 & 190 & 15.1 \\
\hline & & & SW & 1.500 & 162 & 0.020 & 0.040 & 240 & 17.8 \\
\hline 19 & 22 & 20 & NH & 0.639 & 198 & 0.030 & 0.092 & 118 & B. 3 \\
\hline & & & SH & 1.480 & 168 & 0.026 & 0.100 & 194 & 10.4 \\
\hline 20 & 31 & 20 & NH & 1.510 & 156 & 0.039 & 0.099 & 222 & 12.4 \\
\hline & & & SH & 1.170 & 162 & 0.040 & 0.076 & 234 & 13.7 \\
\hline 21 & 20 & 13 & NH & 0.362 & 243 & 0.035 & 0.091 & 137 & 6.3 \\
\hline & & & SH & -0.460 & 234 & 0.042 & 0.142 & 89 & 7.4 \\
\hline 22 & 7 & 3 & NH & 1.380 & 184 & 0.054 & 0.089 & 148 & 14.9 \\
\hline & & & SH & 1.350 & 213 & 0.068 & 0.073 & 98 & 16.9 \\
\hline 23 & 16 & 9 & NH & 1.220 & 172 & 0.044 & 0.082 & 200 & 11.4 \\
\hline & & & SH & 1.720 & 15 & 0.032 & 0.112 & 229 & 13.5 \\
\hline 24 & 21 & 13 & NH & 1.180 & 175 & 0.035 & 0.099 & 160 & 7.0 \\
\hline & & & SH & 1.940 & 180 & 0.043 & 0.131 & 167 & 7.8 \\
\hline 25 & 9 & 8 & NW & -0.015 & 198 & 0.057 & 0.112 & 118 & 7.6 \\
\hline & & & SH & 0.560 & 244 & 0.048 & 0.152 & 146 & 8.3 \\
\hline 26 & 24 & 11 & NH & -0.775 & 236 & 0.112 & 0.251 & 118 & 4.1 \\
\hline & & & SH & 1.940 & 206 & 0.072 & 0.100 & 89 & 5.1 \\
\hline 27 & 25 & 23 & NW & 1.250 & 175 & 0.056 & 0.068 & 180 & 12.4 \\
\hline & & & SH & 0.670 & 172 & 0.041 & 0.082 & 213 & 16.5 \\
\hline 28 & 16 & 10 & NH & 0.096 & 237 & 0.073 & 0.078 & 110 & 9.8 \\
\hline & & & SH & 1.780 & 16 & 0.044 & 0.080 & 203 & 11.3 \\
\hline 29 & 25 & 11 & NH & -0.164 & 225 & 0.079 & 0.090 & 59 & 12.1 \\
\hline & & & SW & 1.100 & 158 & 0.038 & 0.097 & 236 & 13.4 \\
\hline 30 & 4 & 9 & NH & -0.651 & 238 & 0.160 & 0.221 & 130 & 7.8 \\
\hline & & & SH & & (1) & 0.040 & 0.084 & 240 & \\
\hline & & & & & & & & & \\
\hline
\end{tabular}


TABLE 5. Observed and Calculated Monthly Averaged Wind Speeds. The second column lists the monthly averaged speed as calculated by the model, and the third column lists the observed monthly averaged speed.

\begin{tabular}{|c|c|c|c|c|}
\hline $\begin{array}{c}\text { Station } \\
\text { Identification }\end{array}$ & $\begin{array}{l}\text { Modeled } \\
\text { Speed }(\mathrm{m} / \mathrm{s})\end{array}$ & $\begin{array}{c}\text { Observed } \\
\text { Speed (m/s) }\end{array}$ & $\begin{array}{c}\text { Difference } \\
(\mathrm{m} / \mathrm{s})\end{array}$ & $\begin{array}{l}\text { Station } \\
\text { Type (a) }\end{array}$ \\
\hline & & NW DOMAIN & & \\
\hline 1394 & 11.5 & 11.7 & 0.2 & $T$ \\
\hline 1410 & 9.8 & 10.0 & 0.2 & v \\
\hline 1409 & 8.8 & 8.6 & -0.2 & $\mathrm{~T}$ \\
\hline 1407 & 9.0 & 8.3 & -0.7 & v \\
\hline 1406 & 9.0 & 9.5 & 0.5 & $v$ \\
\hline 1416 & 8.4 & 8.3 & -0.1 & $\mathrm{~T}$ \\
\hline 1415 & 8.4 & 8.2 & -0.2 & $v$ \\
\hline 1405 & 8.9 & 9.0 & 0.1 & v \\
\hline 1414 & 8.8 & 8.5 & -0.3 & $\begin{array}{l}y \\
v\end{array}$ \\
\hline $\begin{array}{l}1413 \\
1412\end{array}$ & 8.8 & $\begin{array}{l}8.5 \\
9.1\end{array}$ & $\begin{array}{r}-0.3 \\
0.0\end{array}$ & $\begin{array}{l}v \\
v\end{array}$ \\
\hline $\begin{array}{l}1404 \\
\end{array}$ & 9.1 & 9.3 & 0.2 & v \\
\hline 1401 & 9.1 & 8.7 & -0.4 & $v$ \\
\hline 1400 & 9.6 & 10.3 & 0.7 & v \\
\hline 1402 & 8.7 & 8.2 & -0.5 & T \\
\hline 1403 & & 10.4 & 0.9 & v \\
\hline 1397 & 9.8 & 9.6 & -0.2 & v \\
\hline 1396 & 10.6 & 10.7 & 0.1 & v \\
\hline 1395 & 10.1 & 10.4 & 0.3 & $T$ \\
\hline 1393 & 10.6 & 10.6 & 0.0 & \\
\hline 1390 & 10.1 & 9.1 & -1.0 & v \\
\hline 1379 & 10.7 & 11.1 & 0.4 & $T$ \\
\hline 1391 & 11.2 & 11.2 & 0.0 & v \\
\hline
\end{tabular}

1375

1362

1419

1418

1376

1378

1420

1377

1373

1372

1369

1422

1423

1368

1364
11.5
9.8
8.8
9.0
9.0
8.4
8.4
8.9
8.8
8.8
9.1
9.1
9.1
9.6
8.7
9.5
9.8
10.6
10.1
10.6
10.1
10.7
11.2

10.9

13.2

10.3

10.5

11.7

10.7

11.0

10.6

11.0

11.8

12.6

11.9

12.0

12.6

11.1

SW DOMAIN

10.6

12.8

10.5

10.4

12.1

10.8

10.8

9.5

10.3

10.9

12.5

11.7

11.9

12.2

10.1
$-0.3$

$-0.4$

0.2

$-0.1$

0.4

0.1

$-0.2$

$-1.1$

$-0.7$

$-0.9$

$-0.1$

$-0.2$

$-0.1$

$-0.4$

$-1.0$

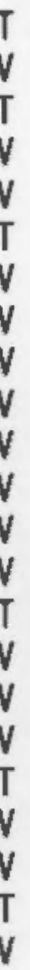

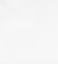



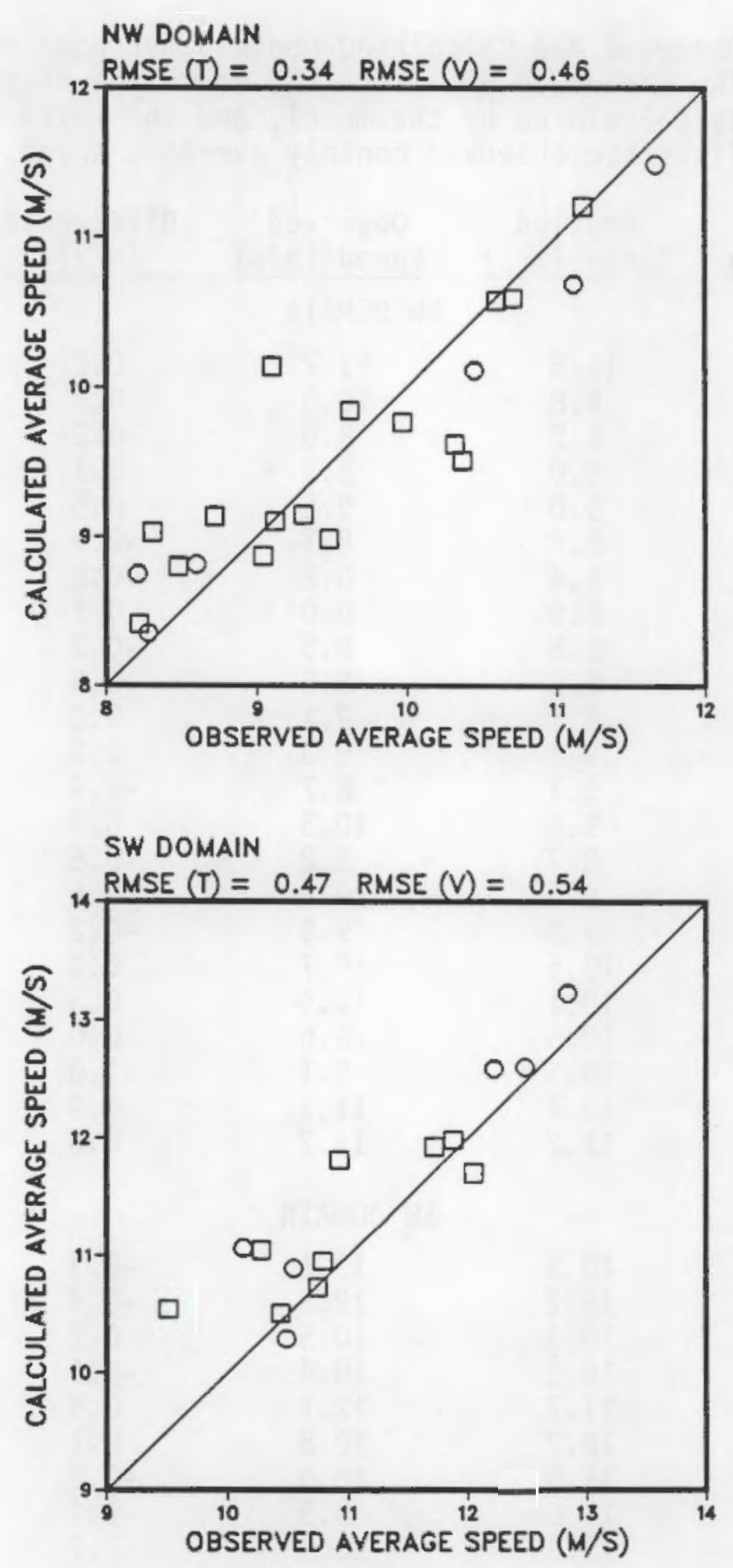

FIGURE 9. Scatter Plots of the Observed Averaged Speed Versus the Calculated Average Speed for the NW and SW Modeling Domains. The circles and squares indicate the tuning and verification sites, respectively. The tuning and verification RMSEs (in $\mathrm{m} / \mathrm{s}$ ) are indicated at the top of each plot. 
characteristic speed for each domain can be taken to be $10 \mathrm{~m} / \mathrm{s}$, and therefore the relative wind speed prediction error (RMSE/characteristic speed) is about $5 \%$ for the two domains. Table 5 indicates that the maximum error in wind speed prediction is about $1.1 \mathrm{~m} / \mathrm{s}$ and occurs for station 1377 in the SW domain. Most errors are significantly less than $1 \mathrm{~m} / \mathrm{s}$. Based on these results, it seems that the model shows definite skill in predicting monthly average speeds at the verification sites. (Modeled and measured wind speed frequency distributions for the stations in the NW and SW domains are shown in Appendix B.)

Model simulations of the average speed for August are shown in Figure 10, where the winds speeds are indicated by $1 \mathrm{~m} / \mathrm{s}$ contours. (In this figure the terrain contours are indicated by the dashed lines.) Flow acceleration is evident near the crests and flanks of the small hills that typify the terrain. For both modeling domains, the terrain slopes downward toward the east, and the higher wind speeds occur in the eastern parts of these domains where the terrain is generally lower in elevation. This is contrary to the increase in speed one would usually expect as the terrain elevation becomes larger.

Table 6 gives data about the model's skill in predicting monthly gross powers at the verification (and tuning) sites; this information is portrayed graphically in the scatter plots shown in Figure 11 . The tuning and verification power RMSE (in $\mathrm{kW}$ ) are shown at the top of each scatter plot, and for both domains the RMSE is about $10 \mathrm{~kW}$. If a characteristic power for both domains is taken to be $90 \mathrm{~kW}$, then the relative prediction error is about $11 \%$. As revealed by Table 6 , most of the absolute prediction errors are less than $12 \mathrm{~kW}$. The largest absolute error $(22 \mathrm{~kW})$ occurs for site 1390 in the NW domain. Figure 12 displays contours of the gross power as predicted by the model for the month of August. As expected, the areas of larger powers are found at locations similar to those for enhanced wind speeds, that is, along the crest and flanks of the terrain features, and furthermore, larger powers are associated with downslope locations. Model output such as embodied in Figure 12 could provide the wind farm developer with a useful guide in locating wind turbines.

Figure 13 is a scatter plot of observed and predicted gross powers for the 26 verification sites of both modeling domains. The model's skill in segregating between poor and good locations is clearly evident. 

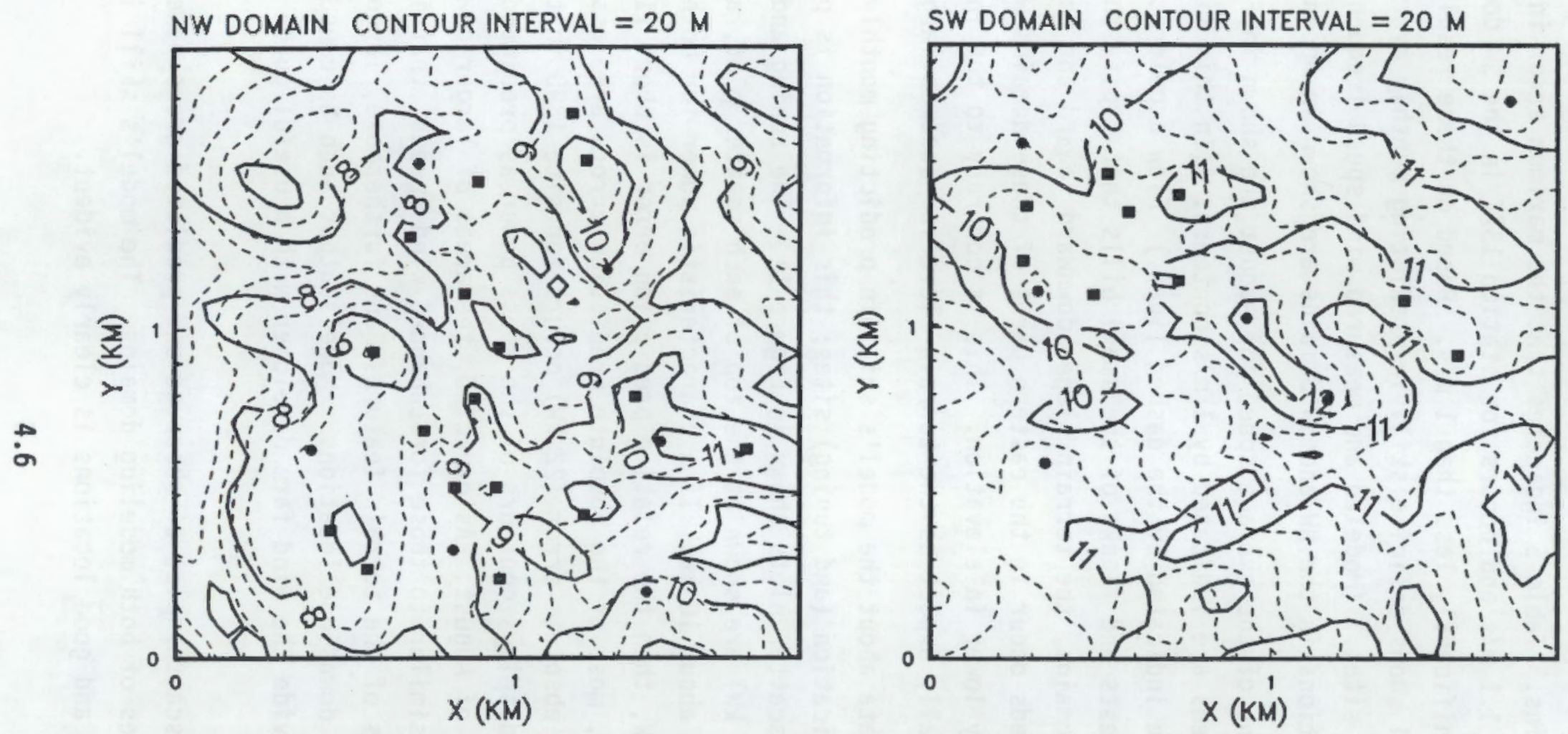

FIGURE 10. Wind Speed Contour Plots for the NH and SH Modeling Domains. The wind speed contour interval is $1 \mathrm{~m} / \mathrm{s}$. The terrain contours (20-m intervals) are shown by the dashed lines. The circles and squares mark the locations of the tuning and verification sites, respectively. 
TABLE 6. Observed and Calculated Monthly Averaged Gross Powers. The second column is the monthly averaged gross power as predicted by the model, and the third column is the gross power that has been calculated from the wind observations.

\begin{tabular}{|c|c|c|c|c|}
\hline $\begin{array}{c}\text { Station } \\
\text { Identification } \\
\end{array}$ & $\begin{array}{l}\text { Modeled } \\
\text { Power (kW) }\end{array}$ & $\begin{array}{l}\text { Observed } \\
\text { Power (kW) }\end{array}$ & $\begin{array}{c}\text { Difference } \\
(\mathrm{kW}) \\
\end{array}$ & $\begin{array}{l}\text { Station } \\
\text { Type (a) }\end{array}$ \\
\hline & & NW DOMAIN & & \\
\hline 1394 & 114 & 118 & 4 & $\mathrm{~T}$ \\
\hline 1410 & 78 & 83 & 5 & v \\
\hline 1409 & 59 & 54 & -5 & $\mathrm{~T}$ \\
\hline 1407 & 62 & 49 & -13 & v \\
\hline 1406 & 61 & 72 & 11 & v \\
\hline 1416 & 53 & 50 & -3 & $T$ \\
\hline 1415 & 52 & 47 & -5 & $V$ \\
\hline 1405 & 59 & 64 & 5 & $v$ \\
\hline 1414 & 61 & 52 & -9 & $v$ \\
\hline 1413 & 59 & 53 & -6 & V \\
\hline 1412 & 65 & 66 & 1 & $v$ \\
\hline 1404 & 65 & 70 & 5 & V \\
\hline 1401 & 64 & 57 & -7 & V \\
\hline 1400 & 74 & 90 & 16 & V \\
\hline 1402 & 57 & 47 & -10 & $\mathrm{~T}$ \\
\hline 1403 & 72 & 91 & 19 & V \\
\hline 1397 & 80 & 78 & -2 & V \\
\hline 1396 & 95 & 99 & 4 & v \\
\hline 1395 & 86 & 95 & 9 & $\mathrm{~T}$ \\
\hline 1393 & 96 & 97 & 1 & V \\
\hline 1390 & 88 & 66 & -22 & V \\
\hline 1379 & 98 & 108 & 10 & $\mathrm{~T}$ \\
\hline 1391 & 109 & 109 & 0 & V \\
\hline
\end{tabular}

SW DOMAIN

$\begin{array}{lrrrr}1375 & 98 & 95 & -3 & \mathrm{~T} \\ 1362 & 141 & 139 & -2 & \mathrm{~T} \\ 1419 & 85 & 94 & 9 & \mathrm{~T} \\ 1418 & 90 & 94 & 4 & \mathrm{~V} \\ 1376 & 115 & 126 & 11 & \mathrm{~V} \\ 1378 & 94 & 99 & 5 & \mathrm{~V} \\ 1420 & 100 & 101 & 1 & \mathrm{~V} \\ 1377 & 90 & 74 & -16 & \mathrm{~V} \\ 1373 & 102 & 89 & -13 & \mathrm{~V} \\ 1372 & 117 & 103 & -14 & \mathrm{~V} \\ 1369 & 131 & 133 & 2 & \mathrm{~T} \\ 1422 & 120 & 120 & 0 & \mathrm{~V} \\ 1423 & 121 & 123 & 2 & \mathrm{~V} \\ 1368 & 130 & 129 & -1 & \mathrm{~T} \\ 1364 & 99 & 86 & -13 & \mathrm{~T}\end{array}$

(a) $T$ = Tuning Site, $V$ = Verification Site. 

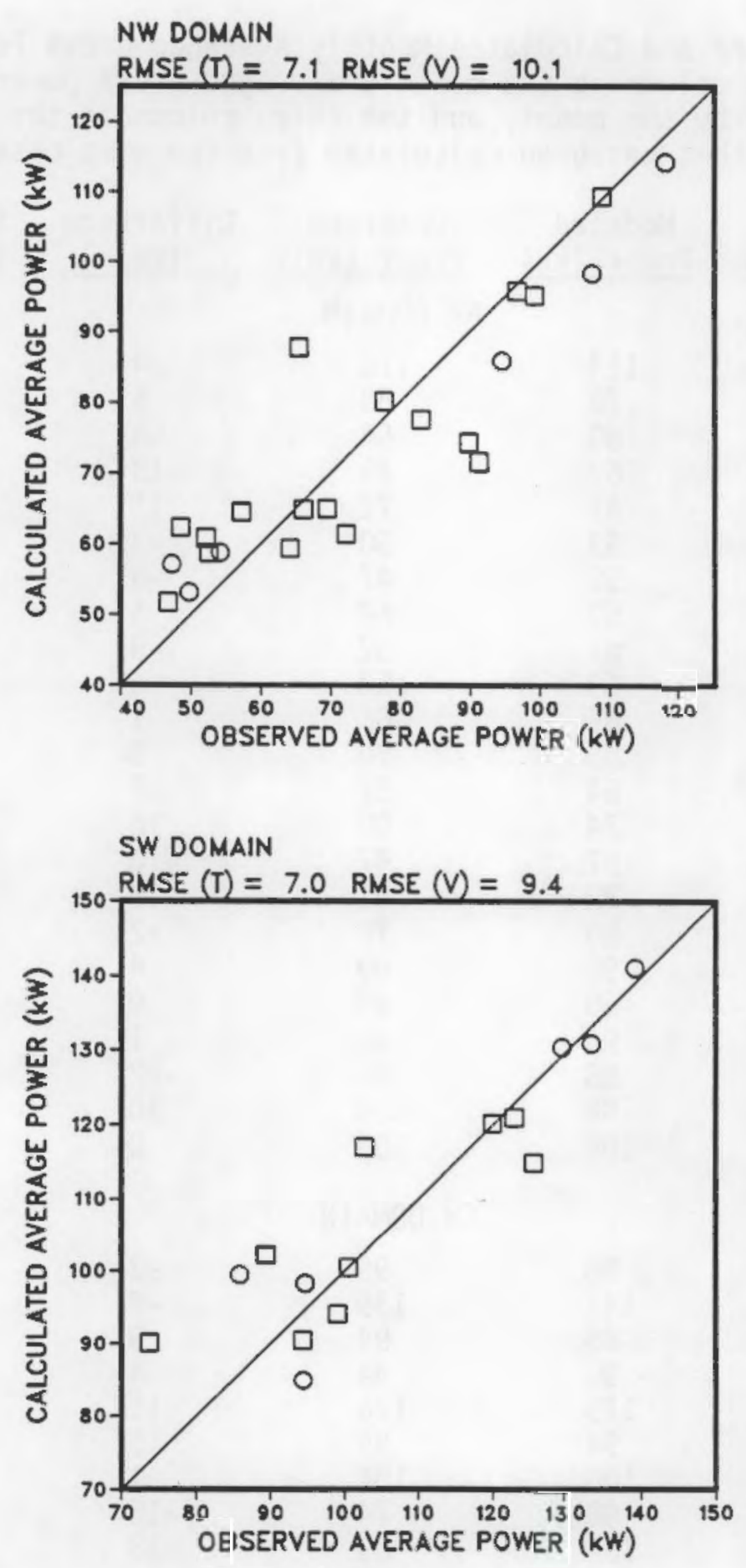

FIGURE 11. Scatter Plots of the Observed Average Gross Power Versus the Model-Calculated Average Gross Power for the NW and SW Modeling Domains. The circles and squares indicate the tuning and verification sites, respectively. The tuning and verification RMSES (in $\mathrm{kW}$ ) are shown at the top of each plot. 

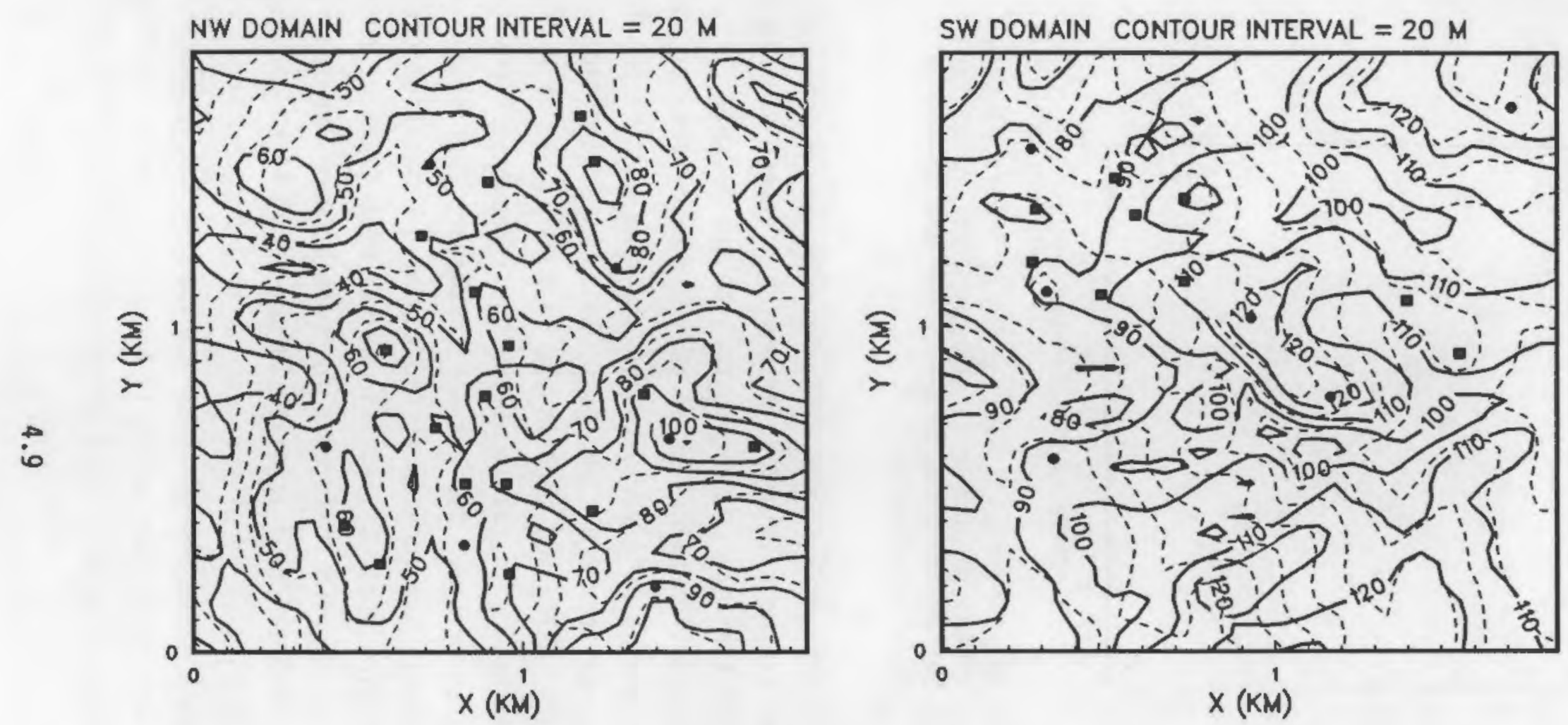

FIGURE 12. Contours (10-kW intervals) for the Average Gross Power for the NW and SW Modeling Domains. The terrain contours (20-m intervals) are shown by dashed lines. The circles and squares mark the locations of the tuning and verification sites, respectively. 


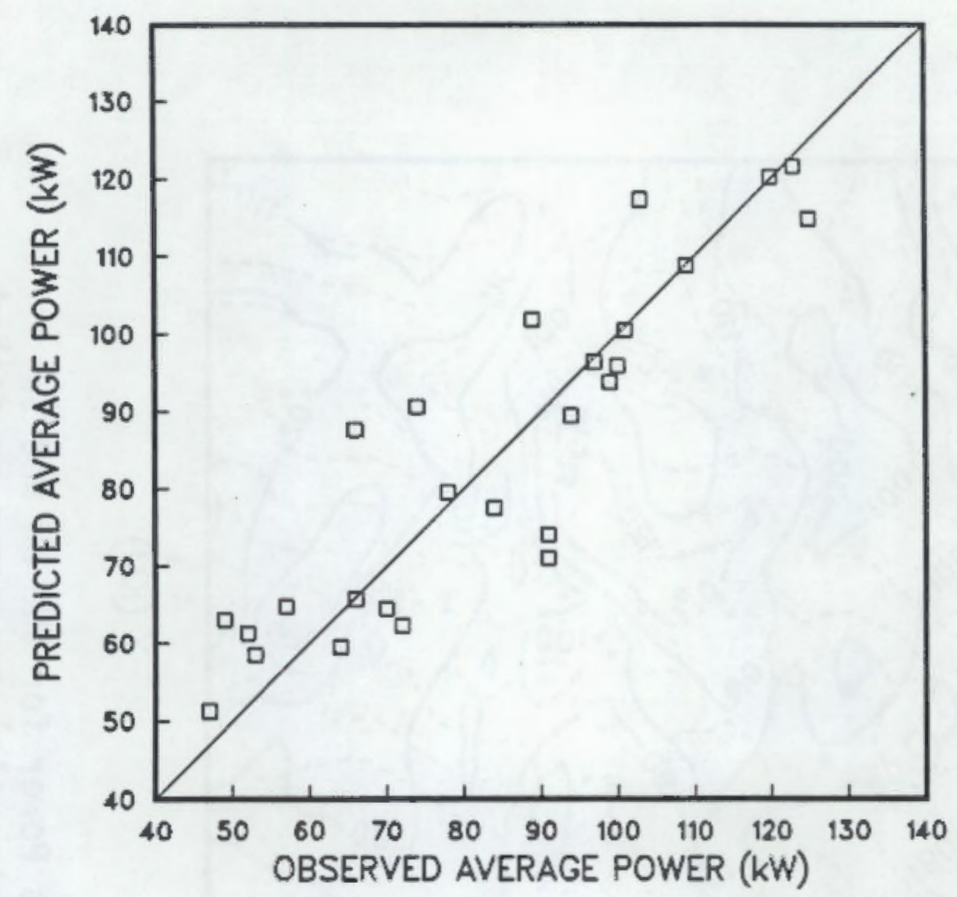

FIGURE 13. Model-Predicted Average Gross Powers Plotted Versus the Observed Average Gross Power for the 26 Verification Sites for the NW and SW Modeling Domains

The locations of the verification stations with the largest absolute errors in gross power can be examined to determine if these locations have common characteristics that may be contributing to the large errors. If a "large error" is arbitrarily defined as an absolute error greater than $11 \mathrm{~kW}$, then Table 6 reveals that 4 or 5 verification stations in each domain have large errors. These stations are 1390, 1400, 1403, 1406, and 1407 in the NW domain, and 1372, 1373, 1376, and 1377 in the SW domain. It is difficult to recognize any common feature in the location of all these stations that would contribute to the large errors. One can note, however, that stations 1400 and 1403 in the NW domain are located at the top of a pronounced terrain feature, and a nearby tuning station (1402) is on the west flank of this feature. In this situation the observed difference in power between the tuning station (1402) and stations 1400 and 1403 is quite large--about $44 \mathrm{~kW}--$ and the model is unable to simulate this large difference. A somewhat similar situation occurs in the SW domain where two stations are located fairly close to the top of a hill (1377 and 1373) upon which is situated a tuning station (1375). In this case, the observed power at the tuning site differs from the observed 
power at the verification sites by $21 \mathrm{~kW}$ and $6 \mathrm{~kW}$ for sites 1377 and 1373, respectively. Again, the difference in modeled powers between tuning site 1375 and the verification site in question is less than the observed difference; it is only $8 \mathrm{~kW}$ for site 1377 and about $4 \mathrm{~kW}$ for site 1373. Based on this information, it appears that the model underestimates the observed variability in the wind power that occurs over the relatively small scale of a terrain feature. On the other hand, the model appears able to portray the variation in the wind that takes place over the entire modeling domain. These idiosyncracies of the model should be kept in mind when applying the model to areas with similar terrain and meteorology.

Wind direction measurements provide a basis with which to check the veracity of the model-derived directions as listed in Table 5 . The modeled directions from the NW domain can be compared with measurements from station 1394, located in the NW domain, while modeled directions in the SW domain can be compared with station 1326, which is located on the northeast edge of this domain. This comparison is shown in Figure 14, where scatter plots of modeled and measured wind directions are shown (within a range of $140^{\circ}$ to $360^{\circ}$ ). This figure reveals that there is little correlation between modeled and measured directions. Also, the model shows a definite proclivity to underpredict the actual direction. For example, in the SW domain, the directions for a majority of the model simulations are between $140^{\circ}$ to $220^{\circ}$, while the measurements made at Station 1326 indicate that the flow for these cases was primarily between the directions of $220^{\circ}$ and $250^{\circ}$.

An explanation of the model's tendency to underpredict the wind direction has not yet been fully developed. A preliminary investigation has indicated that the RMSE that is minimized by the optimization process often has a local minimum around say, $230^{\circ}$, yet a global mimimum (with a lower RMSE) occurs at a much more southerly wind direction of, say, $170^{\circ}$. Because the global minimum is connected with the lowest RMSE, it is the one that is (most often) found by the optimization process. In situations such as these, the wind direction at the local minimum is physically much more realistic, but does not provide the greatest reduction in RMSE. This flaw in the model's performance requires 
NW DOMAIN

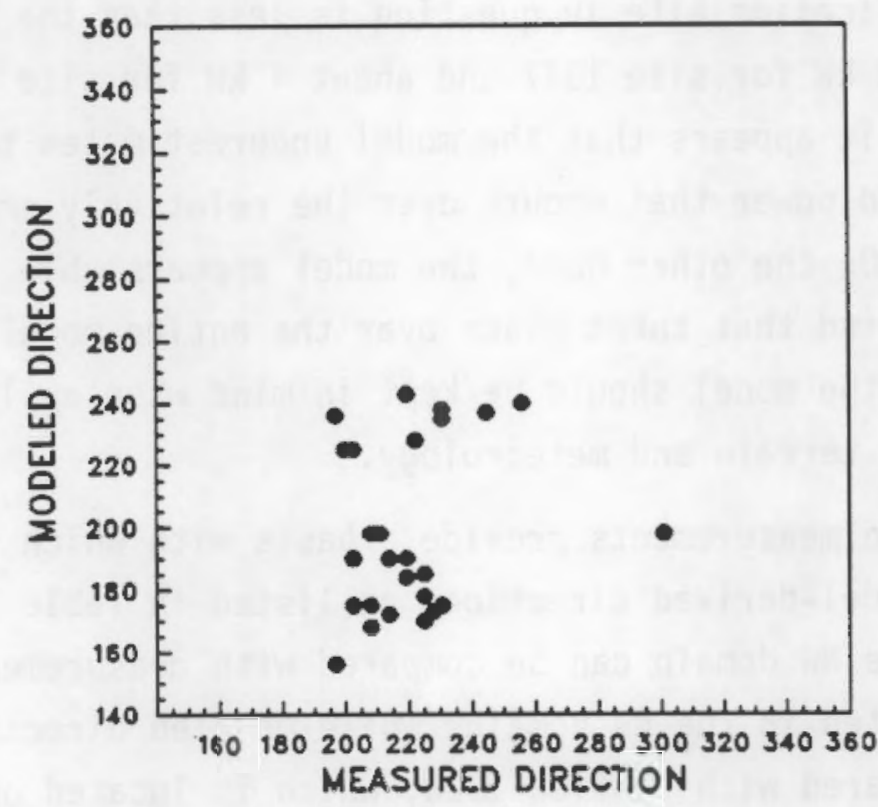

SW DOMAIN

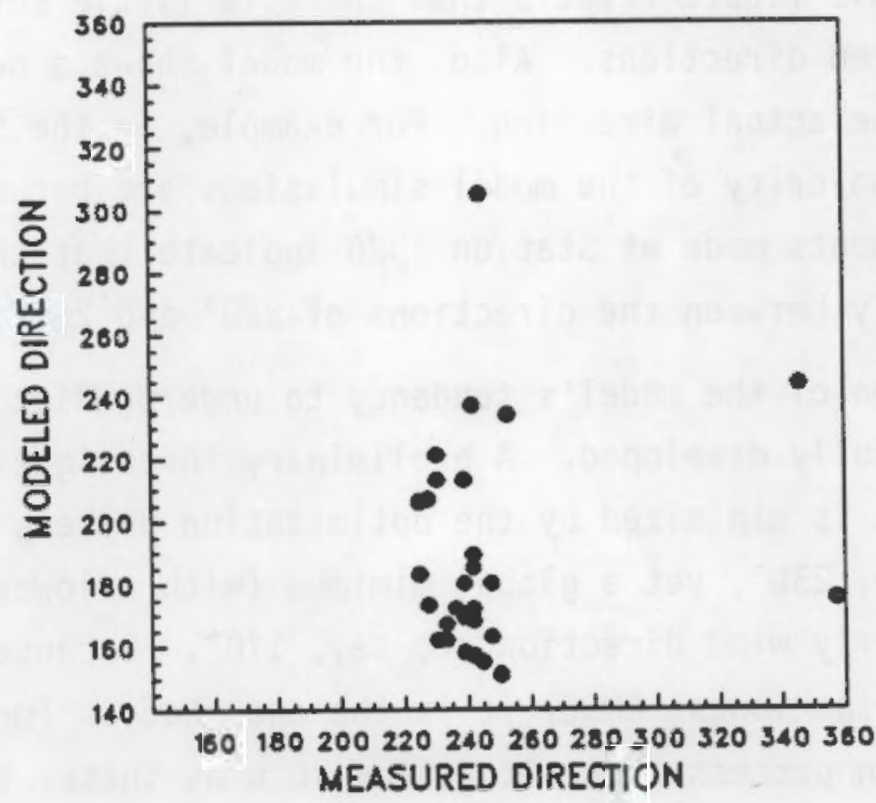

FIGURE 14. Scatter Plots of Measured Wind Direction Versus the Direction Predicted by the Model. There is little or no correlation between these quantities. 
more study. It must be kept in mind, however, that the model's ineptness in predicting directions does not invalidate the skill it demonstrates in predicting wind speeds.

A physical check on the values of the model-derived stability parameter, $\boldsymbol{\tau}$, is not possible because of a complete lack of knowledge of the true atmospheric stability. For a given case, however, a value of $\tau$ derived for one modeling domain should be close the $\tau$ value derived for the other domain. This comparison is performed in the next section.

The CPU usage (VAX 11/780) for each model run is listed in Column 9 of Table 4. Most of the model runs took in excess of 2 hours. Because the model was constructed to demonstrate a "proof of principle"--that optimization can improve model performance--no effort has been directed toward streamlining the model so as to reduce its CPU usage. Significant improvements in this area are a distinct possibility and are necessary if the model is to be used on a regular basis by the wind energy community.

\subsection{VERIFICATION USING MEAN DATA}

This section describes the modeling results when the input to the model consists of mean monthly wind speeds at the tuning sites. The calculated wind field is then a simulation of the actual mean monthly field; from this field the modeled winds at the verification sites can be extracted. Furthermore, the relationship between monthly average speed and gross power described in Section 3.4 .2 allows the computation of modeled gross powers. This approach differs from the method presented in Section 3.4.1, where the model is operated for a small subset of the 744 hourly cases in the month. Using this subset an attempt is made to reconstruct the monthly frequency distributions at the verification sites from which modeled mean speeds and gross powers are calculated. The results presented in this section provide the remaining information needed to compare the accuracy of these two approaches.

The model was operated once in each domain using mean monthly speeds at the tuning sites (these are indicated in Table 2). Table 7 displays the results of model tuning for each domain. The results presented in this table are exactly analogous to those presented in Table 4 . As in the model runs 
TABLE 7. Summary of Modeling Results Using Mean Wind Speeds for Model Input

\begin{tabular}{|c|c|c|c|c|c|c|}
\hline Domain & $T$ & $\theta$ & $\begin{array}{l}\text { Tuning } \\
\text { RMSE } \\
\end{array}$ & $\begin{array}{c}\text { Verification } \\
\text { RMSE } \\
\end{array}$ & $\begin{array}{c}\mathrm{CPU} \\
(\mathrm{min})\end{array}$ & $\begin{array}{l}\text { Speed } \\
(\mathrm{m} / \mathrm{s})\end{array}$ \\
\hline NW & 1.07 & 180 & 0.033 & 0.057 & 191 & 9.7 \\
\hline SW & 1.93 & 170 & 0.018 & 0.045 & 208 & 11.5 \\
\hline
\end{tabular}

using the 30 hourly cases, the reference sites used to calculate the wind speed ratio RMSEs are s tations 1394 and 1375 in the NW and SW domains, respectively. As shown in Table 7 , both the tuning and verification ratio RMSEs are fairly low $(<0.06)$ for the $\mathrm{NW}$ and $\mathrm{SW}$ domains. This indicates that the model performed well using mean monthly data. The tendency of the model to underpredict the actual wind direction still persists when using mean data. If it is assumed that the average monthly direction is about $230^{\circ}$ for both domains, then the model predicts directions that are very much less than this. About 3 hours of CPU time are required for each run.

The performance of the model in predicting average monthly speeds and average gross powers is displayed in Table 8 for the NW domain and Table 9 for the SW domain. The verification RMSEs for the wind speeds are $0.66 \mathrm{~m} / \mathrm{s}$ and $0.46 \mathrm{~m} / \mathrm{s}$ for the NW and SW domains, respectively. These RMSEs are not much different from those obtained using the 30 hourly cases $[0.46 \mathrm{~m} / \mathrm{s}$ (NW domain) and $0.54 \mathrm{~m} / \mathrm{s}$ (SW domain)], and in fact, for the SW domain, the model run using monthly averaged input provides an improved RMSE. Figure 15 displays two scatter plots for both domains that plot calculated average speeds versus observed average speeds. As expected, these scatter plots do not differ greatly from those presented for the winds calculated from the 30 cases (Figure 9).

Modeled and observed gross powers are also listed in Tables 8 and 9 . The RMSEs of the gross powers are $13.4 \mathrm{~kW}$ and $9.4 \mathrm{~kW}$ for the NW and SW domains respectively. How do these compare to the RMSE obtained using the 30 cases? The RMSE for the SW domain is the same as that calculated using the 30 cases-$9.4 \mathrm{~kW}$ for both methods, while for the NW domain the RMSE increases somewhat, from $10.1 \mathrm{~kW}$ ( 30 cases) to $13.4 \mathrm{~kW}$ (mean speeds as input). If as before, it is assumed that for both domains a characteristic power may be taken as $90 \mathrm{~kW}$, 
TABLE 8. Observed and Calculated Monthly Averaged Speeds and Gross Powers for the NW Domain. The modeled quantities were derived from operating the model once using mean speeds as input. RMSE ( $T$ ) and RMSE ( $V$ ) indicate tuning and verification RMSEs, respectively.

\begin{tabular}{|c|c|c|c|c|c|c|c|}
\hline ID & $\begin{array}{l}\text { Modeled } \\
\text { Speed } \\
(\mathrm{m} / \mathrm{s}) \\
\end{array}$ & $\begin{array}{l}\text { Observed } \\
\text { Speed } \\
(\mathrm{m} / \mathrm{s}) \\
\end{array}$ & $\begin{array}{c}\text { Dif. } \\
(\mathrm{m} / \mathrm{s})\end{array}$ & $\begin{array}{l}\text { Modeled } \\
\text { Power } \\
(\mathrm{kW}) \\
\end{array}$ & $\begin{array}{c}\text { Observed } \\
\text { Power } \\
\text { (kW) }\end{array}$ & $\begin{array}{l}\operatorname{Dif} . \\
(\mathrm{KW})\end{array}$ & $\begin{array}{c}\text { Station } \\
\text { Type }\end{array}$ \\
\hline $\begin{array}{l}1394 \\
1410 \\
1409 \\
1407 \\
1406 \\
1416 \\
1415 \\
1405 \\
1414 \\
1413 \\
1412 \\
1404 \\
1401 \\
1400 \\
1402 \\
1403 \\
1397 \\
1396 \\
1395 \\
1393 \\
1390 \\
1379 \\
1391\end{array}$ & $\begin{array}{r}11.7 \\
9.2 \\
9.0 \\
9.0 \\
8.8 \\
8.6 \\
8.3 \\
8.6 \\
9.1 \\
8.4 \\
8.9 \\
8.8 \\
8.9 \\
9.4 \\
8.7 \\
9.1 \\
9.8 \\
10.5 \\
9.9 \\
10.8 \\
10.6 \\
10.9 \\
11.6\end{array}$ & $\begin{array}{r}11.7 \\
10.0 \\
8.6 \\
8.3 \\
9.5 \\
8.3 \\
8.2 \\
9.0 \\
8.5 \\
8.5 \\
9.1 \\
9.3 \\
8.7 \\
10.3 \\
8.2 \\
10.4 \\
9.6 \\
10.7 \\
10.4 \\
10.6 \\
9.1 \\
11.1 \\
11.2\end{array}$ & $\begin{array}{r}0.0 \\
0.8 \\
-0.4 \\
-0.7 \\
0.7 \\
-0.3 \\
-0.1 \\
0.4 \\
-0.6 \\
0.1 \\
0.2 \\
0.5 \\
-0.2 \\
0.9 \\
-0.5 \\
1.3 \\
-0.2 \\
0.2 \\
0.5 \\
-0.2 \\
-1.5 \\
0.2 \\
-0.4\end{array}$ & $\begin{array}{r}119 \\
68 \\
64 \\
63 \\
60 \\
55 \\
50 \\
56 \\
65 \\
52 \\
62 \\
59 \\
62 \\
71 \\
57 \\
65 \\
80 \\
94 \\
81 \\
100 \\
96 \\
102 \\
116\end{array}$ & $\begin{array}{r}118 \\
83 \\
54 \\
49 \\
72 \\
50 \\
47 \\
64 \\
52 \\
53 \\
66 \\
70 \\
57 \\
90 \\
47 \\
91 \\
78 \\
99 \\
95 \\
97 \\
66 \\
108 \\
109\end{array}$ & $\begin{array}{r}-1 \\
15 \\
-10 \\
-14 \\
12 \\
-5 \\
-3 \\
8 \\
-13 \\
-1 \\
4 \\
11 \\
-5 \\
19 \\
-10 \\
26 \\
-2 \\
5 \\
14 \\
-3 \\
-30 \\
6 \\
-7\end{array}$ & $\begin{array}{l}T \\
V \\
T \\
V \\
V \\
T \\
V \\
V \\
V \\
V \\
V \\
V \\
V \\
V \\
T \\
V \\
V \\
V \\
T \\
V \\
V \\
T \\
V\end{array}$ \\
\hline $\begin{array}{l}\text { Speed: } \\
\text { Power: }\end{array}$ & $\begin{array}{l}\text { RMSE (T) } \\
\text { RMSE (T) }\end{array}$ & $\begin{array}{l}=0.38 \mathrm{~m} / \mathrm{s} \\
=8.5 \mathrm{~kW}\end{array}$ & $\begin{array}{l}\text { RMS } \\
\text { RMS }\end{array}$ & $\begin{array}{l}(v)=0 \\
(v)=1\end{array}$ & $\begin{array}{l}5 \mathrm{~m} / \mathrm{s} \\
\mathrm{kW}\end{array}$ & & \\
\hline
\end{tabular}

then the gross power prediction error for both domains combined is about $13 \%$. This is a slight increase over the $11 \%$ associated with the frequency distribution approach.

From these results, it is clear that the use of mean speeds for model input results in little or no decrease in the accuracy of the model. This is an especially fortuitous finding, because it means that the model needs only to be run once for each domain, with a consequent (drastic) reduction in computer and labor costs over the frequency distribution method. 
TABLE 9. Observed and Calculated Monthly Averaged Speeds and Gross Powers for the SW Domain. The modeled quantities were derived from operating the model once using mean speeds as input. RMSE ( $T$ ) and RMSE ( $V$ ) indicate tuning and verification RMSEs, respectively.

\begin{tabular}{|c|c|c|c|c|c|c|c|}
\hline ID & $\begin{array}{c}\text { Modeled } \\
\text { Speed } \\
(\mathrm{m} / \mathrm{s}) \\
\end{array}$ & $\begin{array}{l}\text { Observed } \\
\text { Speed } \\
(\mathrm{m} / \mathrm{s}) \\
\end{array}$ & $\begin{array}{c}\text { Diff } \\
(\mathrm{m} / \mathrm{s})\end{array}$ & $\begin{array}{l}\text { Modeled } \\
\text { Power } \\
(\mathrm{kW}) \\
\end{array}$ & $\begin{array}{c}\text { Observed } \\
\text { Power } \\
\text { (kW) } \\
\end{array}$ & $\begin{array}{l}\text { Dif. } \\
\text { (kW) }\end{array}$ & $\begin{array}{c}\text { Station } \\
\text { Type } \\
\end{array}$ \\
\hline $\begin{array}{l}1375 \\
1362 \\
1419 \\
1418 \\
1376 \\
1378 \\
1420 \\
1377 \\
1373 \\
1372 \\
1369 \\
1422 \\
1423 \\
1368 \\
1364\end{array}$ & $\begin{array}{l}10.5 \\
12.8 \\
10.2 \\
10.6 \\
11.6 \\
10.5 \\
11.0 \\
10.3 \\
10.9 \\
11.7 \\
12.2 \\
11.9 \\
11.9 \\
12.2 \\
10.4\end{array}$ & $\begin{array}{r}10.6 \\
12.8 \\
10.5 \\
10.4 \\
12.1 \\
10.8 \\
10.8 \\
9.5 \\
10.3 \\
10.9 \\
12.5 \\
11.7 \\
11.9 \\
12.2 \\
10.1\end{array}$ & $\begin{array}{r}0.1 \\
0.0 \\
0.3 \\
-0.2 \\
0.5 \\
0.3 \\
-0.2 \\
-0.8 \\
-0.6 \\
-0.8 \\
0.3 \\
-0.2 \\
0.0 \\
0.0 \\
-0.3\end{array}$ & $\begin{array}{r}94 \\
141 \\
88 \\
95 \\
117 \\
93 \\
105 \\
90 \\
102 \\
119 \\
129 \\
121 \\
123 \\
128 \\
92\end{array}$ & $\begin{array}{r}95 \\
139 \\
94 \\
94 \\
126 \\
99 \\
101 \\
74 \\
89 \\
103 \\
133 \\
120 \\
123 \\
129 \\
86\end{array}$ & $\begin{array}{r}1 \\
-2 \\
6 \\
-1 \\
9 \\
6 \\
-4 \\
-16 \\
-13 \\
-16 \\
4 \\
-1 \\
0 \\
1 \\
-6\end{array}$ & $\begin{array}{l}T \\
T \\
T \\
V \\
V \\
V \\
V \\
V \\
V \\
V \\
V \\
T \\
V \\
V \\
V \\
T \\
T\end{array}$ \\
\hline $\begin{array}{l}\text { Speed: } \\
\text { Power: }\end{array}$ & $\begin{array}{l}\text { RMSE }(T) \\
\text { RMSE }(T)\end{array}$ & $\begin{array}{l}=0.21 \mathrm{~m} / \mathrm{s} \\
=4.4 \mathrm{~kW}\end{array}$ & & $\begin{aligned}(V) & =0 \\
(V) & =9\end{aligned}$ & $6 \mathrm{~m} / \mathrm{s}$ & & \\
\hline
\end{tabular}



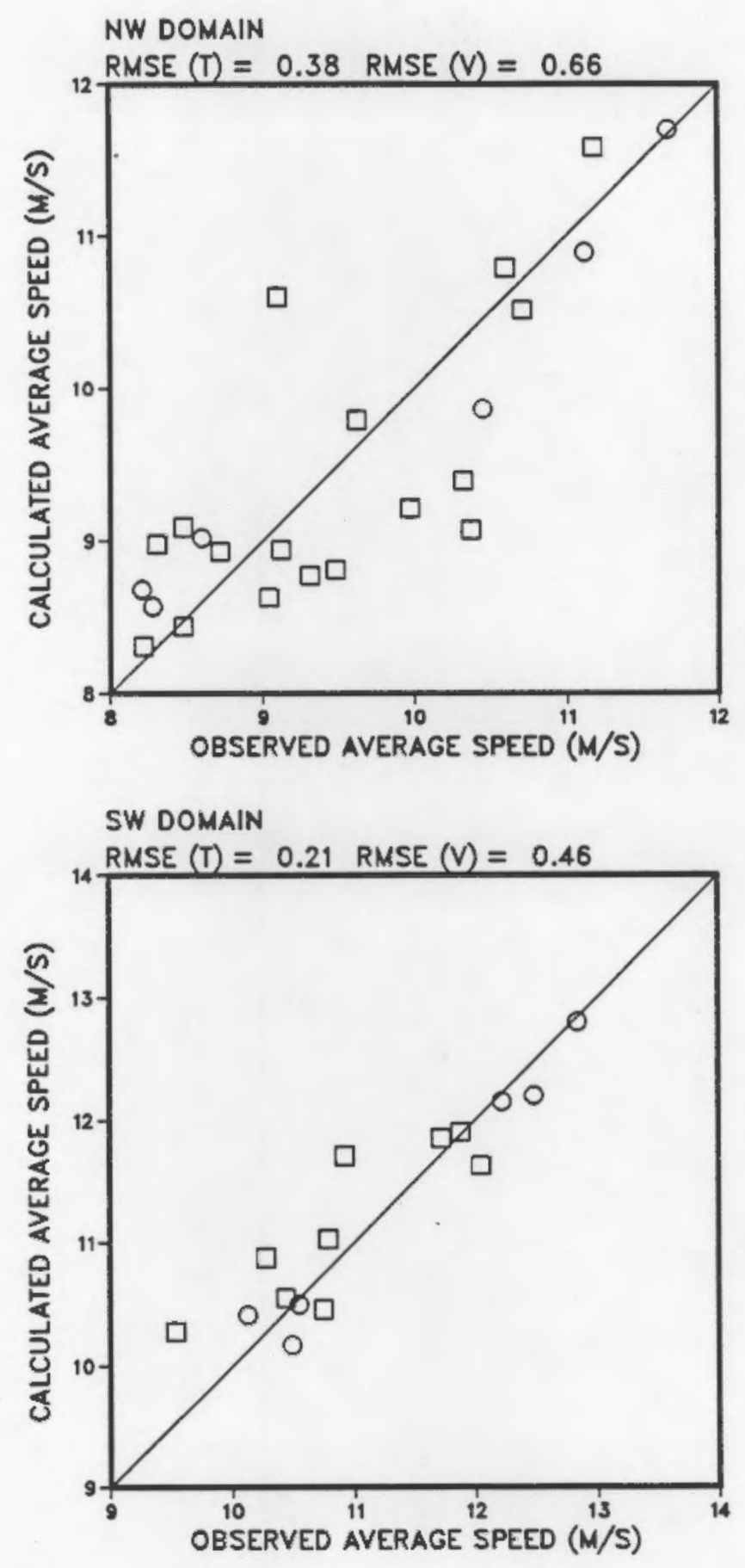

FIGURE 15. Scatter Plots of the Observed Averaged Speed Versus the Calculated Average Speed for the NW and SW Modeling Domains. The calculated speeds were derived by operating the model once using mean speeds as input. The circles and squares indicate the tuning and verification sites, respectively. The tuning and verification RMSES (in $\mathrm{m} / \mathrm{s}$ ) are indicated at the top of each plot. 



\subsection{IMPORTANT POINTS ABOUT MODEL APPLICATION}

When applying the model there are a number of things that should be recognized. The first of these is the effect on the results of changing the location of the tuning sites. If the model results are very sensitive to the location of the tuning sites, then guidance must be provided so that the tuning sites can be located at places that will tend to enhance the model's performance. Second, it is important to determine if the optimum $\tau$ and $\theta$ calculated for a given domain at a particular time can be applied to a nearby domain for the same time period. If this is the case, then the optimization need not be repeated for the second domain, and therefore a considerable amount of computer time is saved.

\subsection{DIFFERENT TUNING SITES}

To examine the effect of the location of tuning sites on the modeled gross powers, the locations of 3 of the 6 tuning sites in the NW domain were altered. For this exercise the tuning sites 1402, 1409, and 1416 were regarded as verification sites, and verification sites 1403, 1410, and 1413 became tuning sites, so that the 6 tuning sites consisted of stations 1379, 1394, $1395,1403,1410$, and 1413. All other stations were verification stations. Again the model was operated for the 30 cases of hourly averaged wind speeds as listed in Table 3 . (These 30 cases should provide a good representation of the power-producing winds during the month, regardless of what tuning sites are used.) Calculated average gross powers were compared to observed gross powers; these quantities are listed in Table 10, and a scatter plot of calculated versus observed powers is shown in Figure 16. As is readily apparent, the use of the new tuning sites causes a definite degradation of model performance; this is quantitatively confirmed by the verification RMSE that increases from about $10 \mathrm{~kW}$ (old tuning sites) to $15 \mathrm{~kW}$ (new tuning sites).

It is interesting to note that the prediction errors in excess of $20 \mathrm{~kW}$ are associated with stations $(1401,1402,1407,1409)$ that are clustered together in the southwest quadrant of the modeling domain, and furthermore, the modeled powers are all much greater than the observed powers. A plausible explanation for this overprediction is that the tuning stations $(1410,1403)$ 
TABLE 10. Observed and Calculated Monthly Averaged Gross Powers for a Different Set of Tuning Sites. The second column is the monthly averaged gross power as predicted by the model, and the third column is the gross power that has been calculated from the wind observations.

$\begin{array}{ccccc}\begin{array}{c}\text { Station } \\ \text { Identification }\end{array} & \begin{array}{c}\text { Modeled } \\ \text { Power } \\ (\mathrm{kW})\end{array} & \begin{array}{c}\text { Observed } \\ \text { Power } \\ (\mathrm{kW})\end{array} & \begin{array}{l}\text { Difference } \\ (\mathrm{kW})\end{array} & \begin{array}{l}\text { Station } \\ \text { Type }(\mathrm{a})\end{array} \\ \end{array}$

NW DOMAIN

$\begin{array}{rrrrr}1410 & 86 & 83 & -3 & T \\ 1394 & 109 & 118 & 9 & \mathrm{~T} \\ 1409 & 75 & 54 & -21 & \mathrm{~V} \\ 1407 & 83 & 49 & -34 & \mathrm{~V} \\ 1406 & 82 & 72 & 10 & \mathrm{~V} \\ 1416 & 59 & 50 & -9 & \mathrm{~V} \\ 1415 & 59 & 47 & -12 & \mathrm{~V} \\ 1405 & 67 & 64 & -3 & \mathrm{~V} \\ 1414 & 57 & 52 & -5 & \mathrm{~V} \\ 1413 & 51 & 53 & 2 & \mathrm{~T} \\ 1412 & 60 & 66 & 6 & \mathrm{~V} \\ 1404 & 66 & 70 & 4 & \mathrm{~V} \\ 1401 & 78 & 57 & -21 & \mathrm{~V} \\ 1400 & 85 & 90 & 5 & \mathrm{~V} \\ 1402 & 77 & 47 & -30 & \mathrm{~V} \\ 1403 & 88 & 91 & 3 & \mathrm{~T} \\ 1397 & 78 & 78 & 0 & \mathrm{~V} \\ 1396 & 90 & 99 & 9 & \mathrm{~V} \\ 1395 & 81 & 95 & 14 & \mathrm{~T} \\ 1393 & 95 & 97 & 2 & \mathrm{~V} \\ 1390 & 83 & 66 & -17 & \mathrm{~V} \\ 1379 & 94 & 108 & 14 & \mathrm{~T} \\ 1391 & 103 & 109 & 6 & \mathrm{~V}\end{array}$

(a) $\quad T=$ Tuning Site, $V=$ Verification Site.

in this vicinity, to which the model is tuned, are located at the top of hills and have a higher wind speed than the lower elevation verification sites. Modeled winds at the these verification sites, located near the two tuning sites with high wind speeds, will therefore tend to be too large, even after the adjustment to make the wind field mass-consistent is made. To add further credibility to this argument, when the model is tuned to the low elevation sites in the southwest quadrant $(1402,1409)$, the predicted speeds at the higher elevation sites $(1400,1403)$ are much too low (see Table 6$)$. It seems reasonable that if the tuning procedure is to work well, then it is desirable 


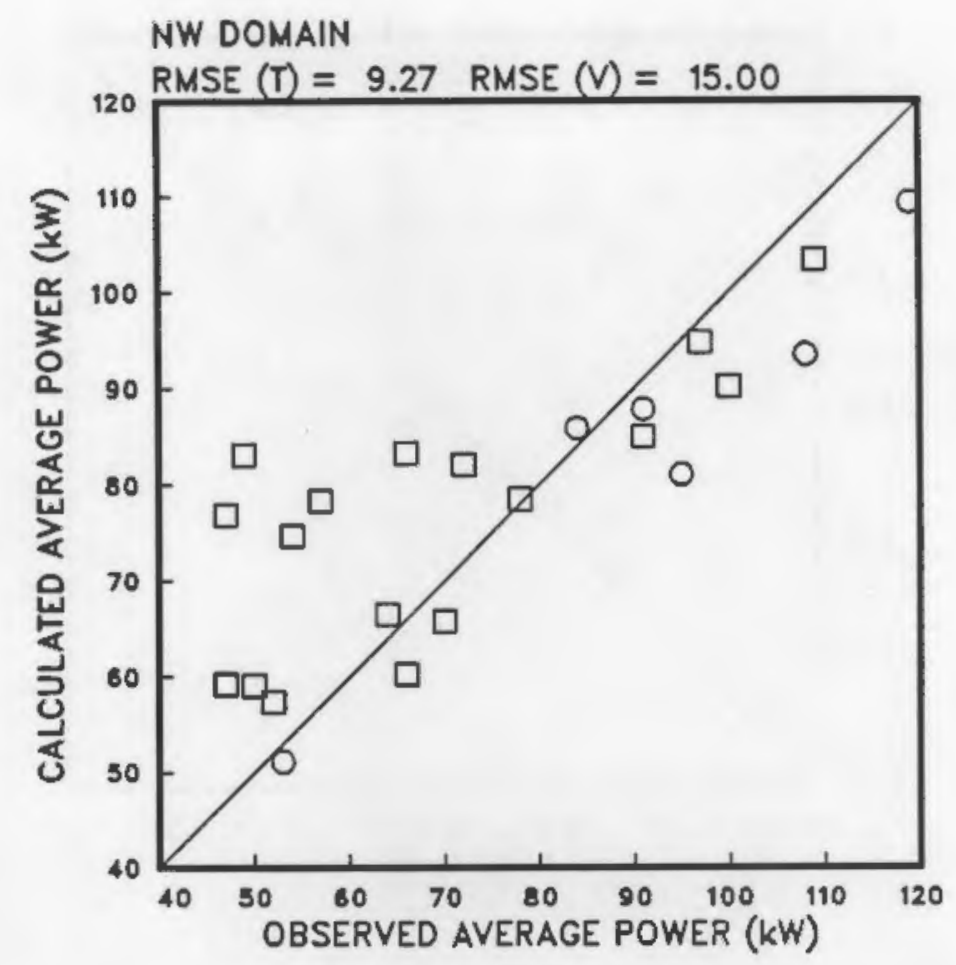

FIGURE 16. Scatter Plot of the Observed Average Gross Power Versus the Model-Calculated Average Gross Power for the NW Domain When a Different Set of Tuning Sites is Used for Model Tuning

that tuning sites be placed in areas of both high and low wind speeds, so that the calculated field will retain the variability in the flow as characterized by the tuning sites. This conclusion should be substantiated by further research.

\subsection{CORRELATION BETWEEN MODEL PARAMETERS OBTAINED FROM DIFFERENT DOMAINS}

Optimum values for $\tau$ and $\theta$ for the two modeling domains and for the 30 cases are listed in Table 4. Can optimum values for these parameters derived for one domain, for example the NW domain, then be applied to a nearby domain, such as the SW domain? This question can be answered by examining the correlation of $\tau$ ( or $\theta$ ) between the two domains; this correlation is shown graphically in Figure 17 where $\tau$ (or $\theta$ ) for the NW domain is plotted against $\tau(\operatorname{or} \theta)$ for the SW domain. For these plots, $\tau$ and $\theta$ values were not included unless the average speed for the 12 tuning sites exceeded the cut-in speed of the turbines, which was taken to be $7 \mathrm{~m} / \mathrm{s}$. The dashed line in these plots 

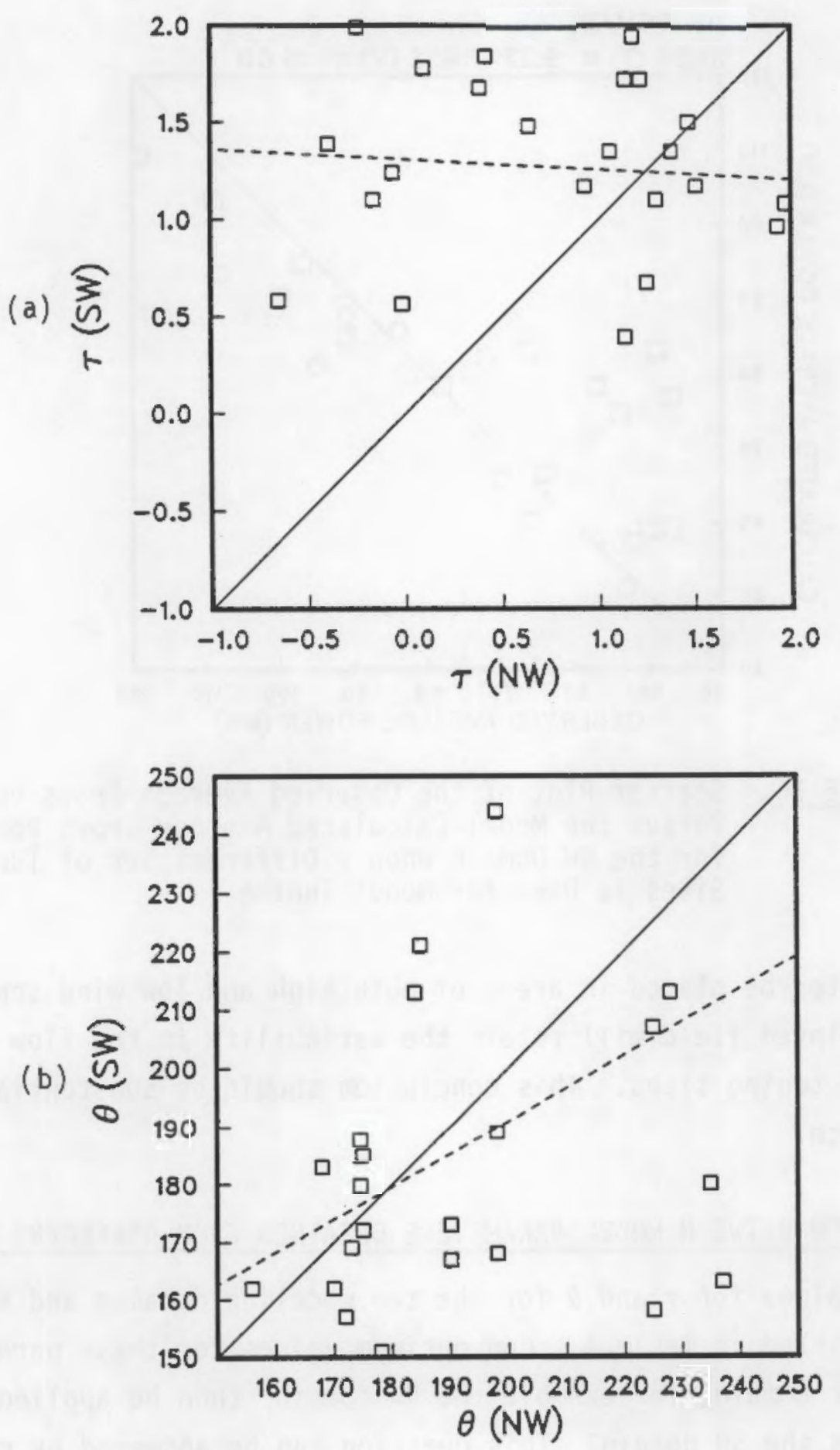

FIGURE 17. Scatter Plot of the Optimum Value of (a) $\tau$ for the SW Domain Plotted Against the Optimum Value of $\tau$ for the NW Domain, and (b) $\theta$ for the SW Domain Against the Optimum Value of $\theta$ for the NW Domain. The dashed line in each plot is a line of regression fit to these data. 
is a line of regression fit to these data. It is obvious that there is no correlation at all between $\tau$ of different domains, and this is quantitatively substantiated by the value of the correlation coefficient, $r^{2}$, which is 0.007 . Only a weak correlation exists between $\theta$ values; in this case $r^{2}$ is 0.17 . For these two domains, model parameters appropriate for one domain are not appropriate for the other. This lack of correlation is disappointing and at the present time it is difficult to formulate reasons to explain it.

From a physical point of view, it would be much more pleasing if the correlation between the $\theta \mathrm{s}$ (and $\tau \mathrm{s}$ ) of the two modeling domains were much higher. However, for almost all situations to which the model may be applied, model predictions of $\tau$ are irrelevant. Additionally, there are many circumstances where the wind direction over the site is known, or if it is unknown, its value is not of great concern, and in these cases, model-derived values of $\theta$ become unimportant. Thus, the model's difficulty with predictions of $\tau$ and $\theta$ does not necessarily detract from its usefulness for those situations where predictions of wind speeds alone are of primary importance; in this regard the model shows definite skill. 



\subsection{CONCLUSIONS AND RECOMMENDATIONS}

\subsection{CONCLUSIONS}

This report has examined the ability of the optimizing NOABL model to simulate the wind speed and gross wind power over an area of complex terrain considered for wind energy development. The foundation for this verification study was a set of wind speed observations made in the Altamont Pass area of California; this set consists of hourly averaged wind speeds obtained from about 60 sites during the entire month of August 1985. About two-thirds of the 60 stations were used in this study. It was not possible to model the entire area over which observations were made because of limitations on computer time. Two smaller areas, called the NW and SW modeling domains, were selected and the model was applied to these areas using two approaches. The first approach used a condensed set of wind data, 30 hourly cases out of a possible 744 hours, to represent the primary power-producing flow patterns during the month of August. With the second approach, the model was operated only once for each domain using monthly averaged speeds as input. The ability of the model to predict speeds and gross powers at places away from the tuning sites was accomplished by comparing calculated values of these quantities to observed values at observation sites that were termed verification sites. In general, each operation of the model required a considerable amount of computer time (VAX 11/780), and many of the runs were in excess of 2 hours.

The RMSEs between model predictions of average monthly speed and the actual speed were about $0.5 \mathrm{~m} / \mathrm{s}$, regardless of which approach was used. Average speeds over the modeling domains are on the order of $10 \mathrm{~m} / \mathrm{s}$, so that the prediction error in percent is about $5 \%$. The average gross powers as predicted from the model-derived winds were then compared to "observed" gross powers calculated using a turbine power curve and the observed wind speed frequency distribution. For the first approach the RMSE between actual and predicted gross powers was about $10 \mathrm{~kW}$ for both domains. The observed gross powers are on the order of $90 \mathrm{~kW}$, so the prediction error for gross power is about $11 \%$ For the second approach, the power RMSE for the SW domain remained about $10 \mathrm{~kW}$, however, for the $\mathrm{NW}$ domain it was about $13 \mathrm{~kW}$, an increase above the $10 \mathrm{~kW}$ obtained using the 30 cases. The overall prediction error for the second 
approach is about $13 \%$. It is encouraging that good results were obtained using mean data, because of the drastically reduced computer costs associated with this method. The model seems most proficient at simulating the largescale flow variability over a modeling domain; in contrast, it is not very skillful in depicting smaller scale wind speed variations that may occur over distances of about $100 \mathrm{~m}$.

The sensitivity of the modeled winds to the location of the tuning sites was investigated by changing the location of some of the tuning sites in the NW modeling domain. This had a substantial impact on the model-derived gross powers; the RMSE square error increased from about $10 \mathrm{~kW}$ to about $15 \mathrm{~kW}$. It therefore appears that the location of tuning sites must be chosen with some care, and that some sites should be situated in areas of suspected low wind speeds while the remainder should be placed where the speed may be relatively high.

There is little or no correlation between the optimum values of $\tau$ (or $\theta$ ) derived for one modeling area and the optimum values of these parameters calculated for an adjacent area. Therefore a value of $\tau$ (or $\theta$ ) obtained for one area may not be applicable to another.

\subsection{RECOMMENDATIONS}

The results of this verification study have generated a number of recommendations. In order of priority, these are:

- Feedback must be received from the wind energy community as to whether these results are of sufficient accuracy to be useful to them. If the results are not useful, then the model must either be improved or abandoned.

- These modeling results should be compared to the modeling results obtained from other numerical models to determine which model exhibits the best performance and ease of use. It is highly desirable that all the model comparisons be performed using an identical wind data set such as the one discussed in Chapter 2 of this report. 
- Because of the sensitivity of the modeled winds to the tuning site locations, it is necessary to determine guidelines pertaining to the appropriate positioning of these sites.

- The model should be modified so that it does not require as much computer time and is easier to use. This might speed its acceptance by the wind energy community.

- The lack of correlation between optimum values of $\tau$ (or $\theta$ ) obtained from nearby modeling domains should be explained. 



\subsection{REFERENCES}

Barnard, J. C., H. L. Wegley and T. R. Hiester. 1987. "Improving the Performance of Mass-Consistent Numerical Models Using Optimization Techniques." Journal of Climate and Applied Meteorology 26(6):675-686.

Hardy, D. M., and J. J. Walton. 1978. "Principal Component Analysis of Vector Wind Measurements." Journal of Applied Meteorology 17:1153-1162.

Traci, R. M., G. T. Phillips and P. C. Patnaik. 1978. Developing a Site Selection Methodology for Wind Energy Conversion Systems. DOE/ET/20280-3, National Technical Information Service, Springfield, Virginia.

Willmott, C. J. 1984. "On the Evaluation of Model Performance in Physical Geography." Spatial Statistics and Models, G. L. Gaile and C. J. Willmott, eds., pp. 443-46D, D. Reidel Publishing Co., Dordrecht, The Netherlands.

Willmott, C. J., S. G. Ackleson, R. E. Davis, J. J. Feddema, K. M. Klink, D. R. Legates, J. O'Donnell and C. M. Rowe. 1985. "Statistics for the Evaluation and Comparison of Models." Journal of Geophysical Research $90($ C5) : 8995-9005. 
APPENDIX A

WIND SPEED FREQUENCY DISTRIBUTIONS 
APPENDIX A

\section{WIND SPEED FREQUENCY DISTRIBUTIONS}

This appendix contains plots of the wind speed frequency distributions of the 51 observation sites with a full complement of 744 hours of data. To form the distributions, the hourly data at each site are binned at intervals of $0.447 \mathrm{~m} / \mathrm{s}$ (i.e., $1 \mathrm{mph}$--the data were originally recorded in $\mathrm{mph}$ ). These distributions are discrete distributions, and the distribution can only assume non-zero values at discrete values of the independent variable (i.e., every $1 \mathrm{mph}$ ). However, to better illustrate the shape of the distributions the points that represent the distribution are connected by a curve (i.e., a straight line between adjacent points).

Also shown by dashed lines are Weibull distributions fit to the observed distributions. The average speed $(V)$ and standard deviation $(\sigma)$, and the Weibull $C$ and $K$ for the site in question, are indicated above each plot. 


\section{FREQUENCY (\%) VERSUS WIND SPEED (M/S)}
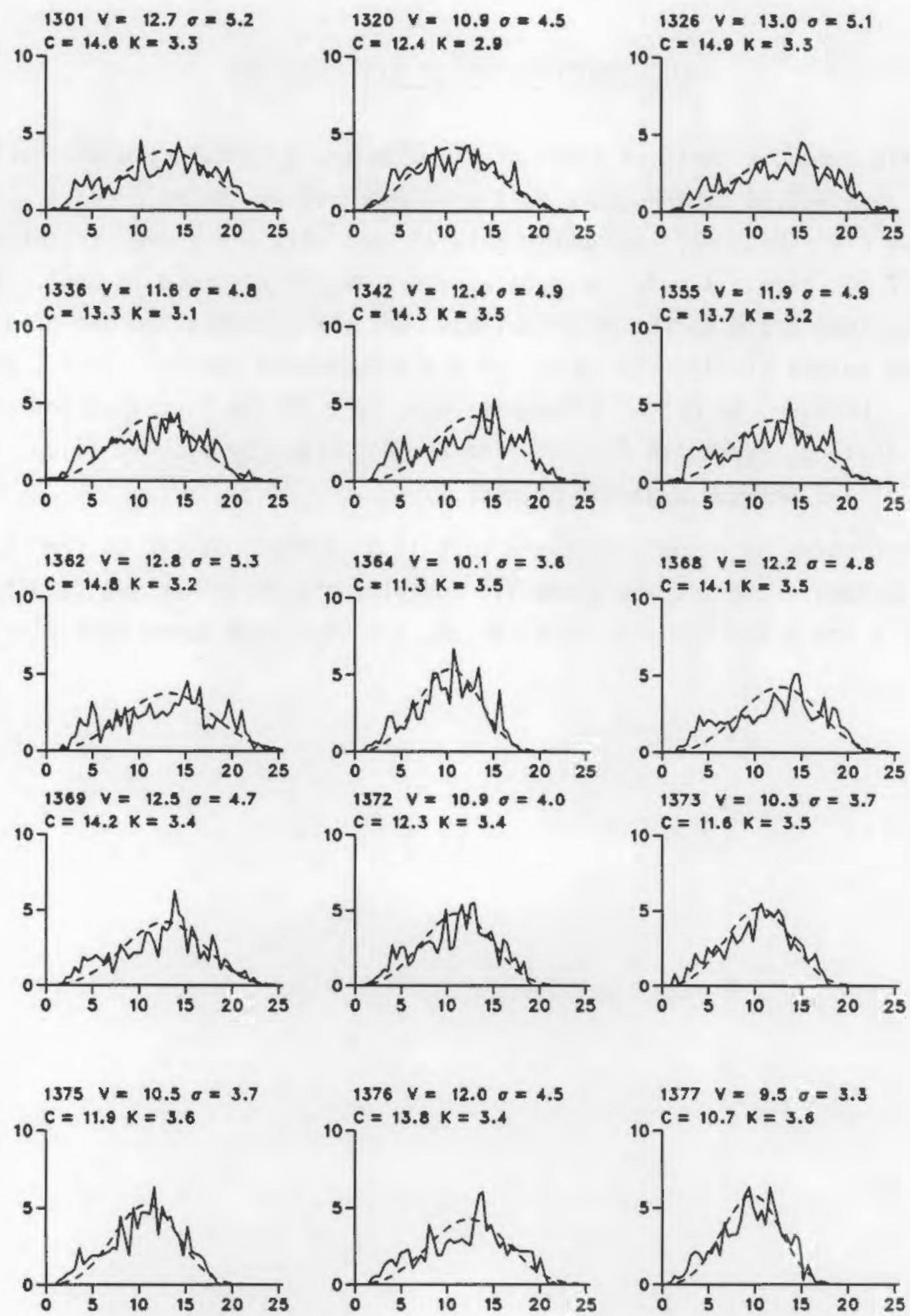


\section{FREQUENCY (\%) VERSUS WIND SPEED (M/S)}
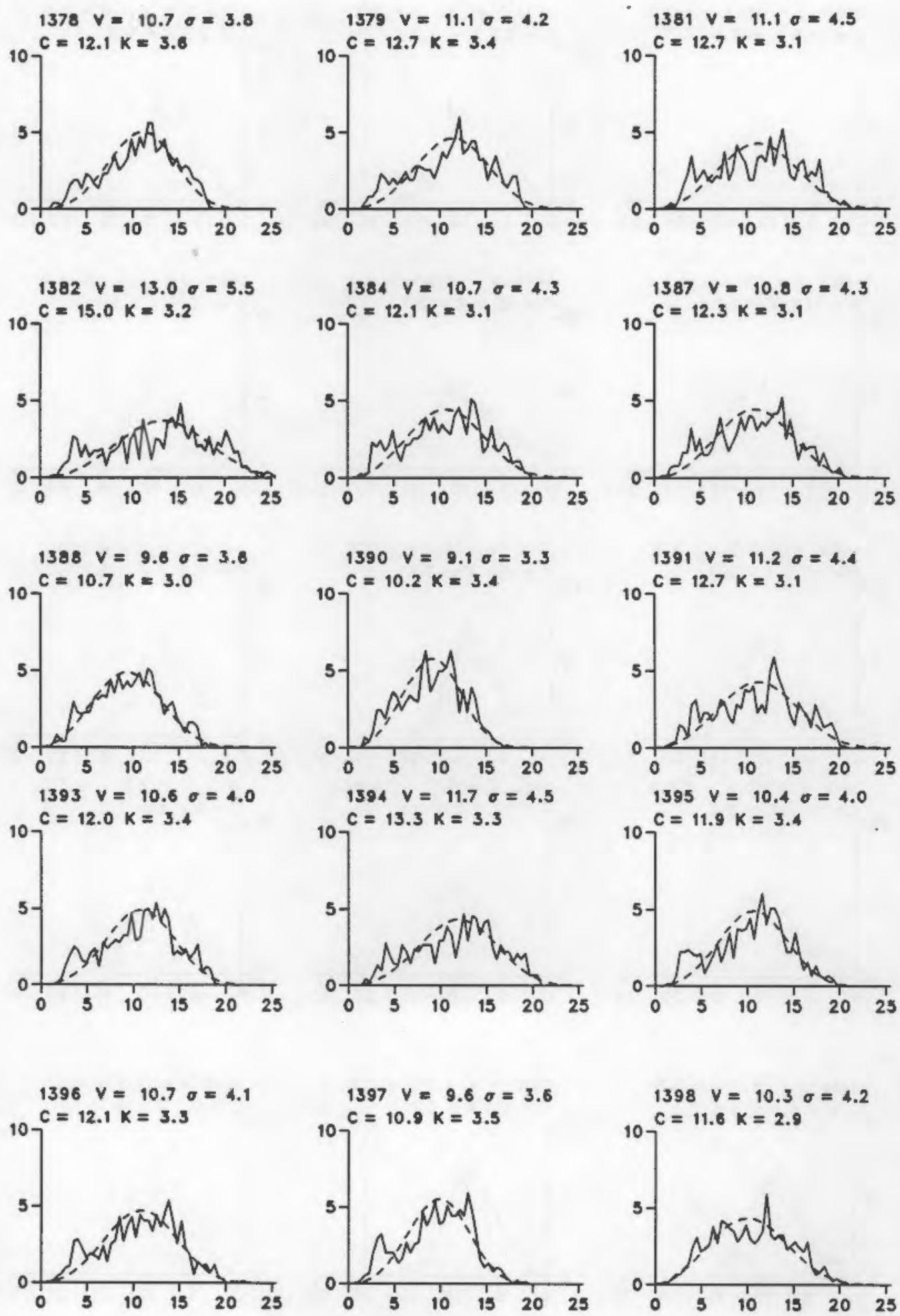


\section{FREQUENCY (\%) VERSUS WIND SPEED (M/S)}
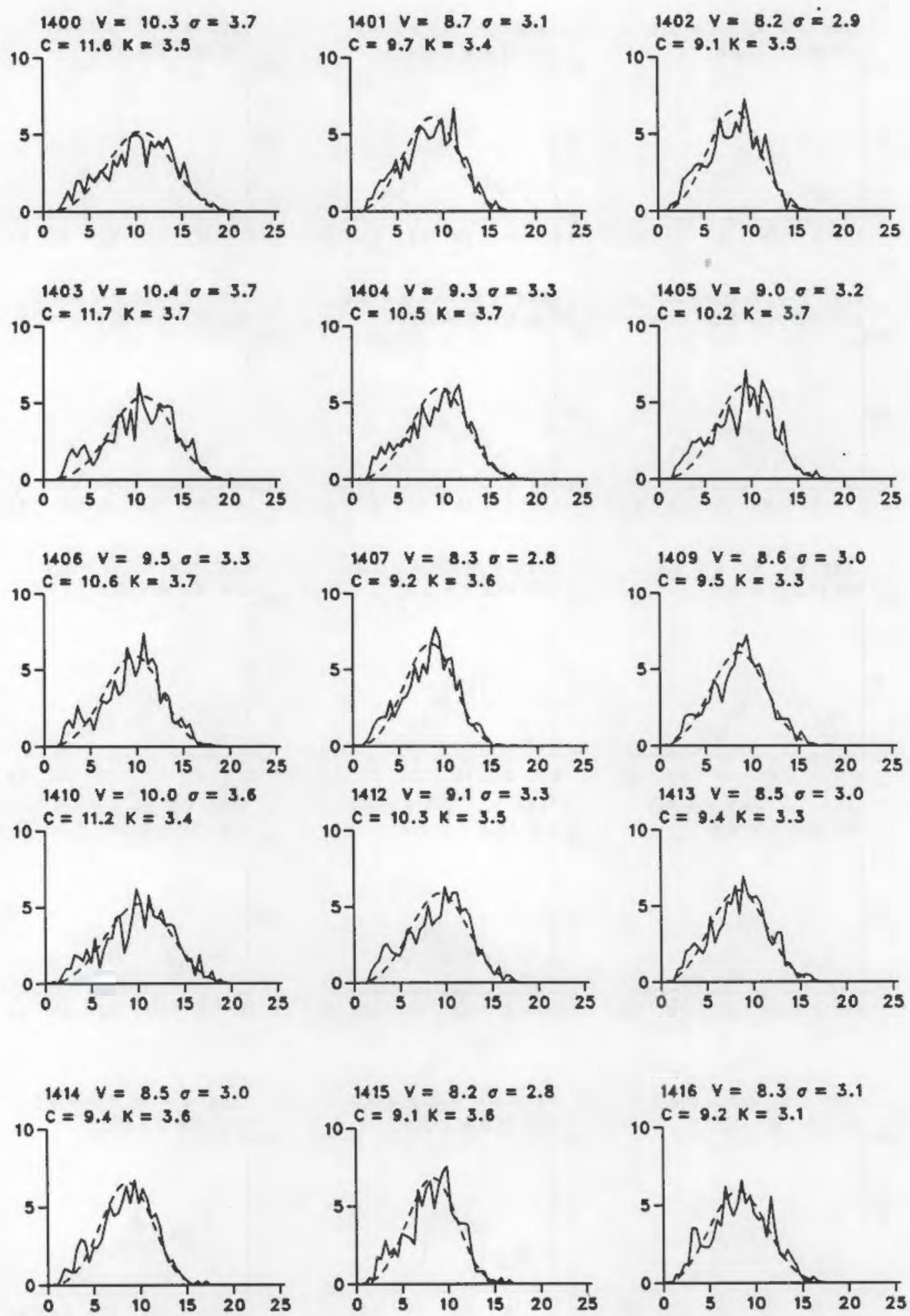


\section{FREQUENCY (\%) VERSUS WIND SPEED (M/S)}
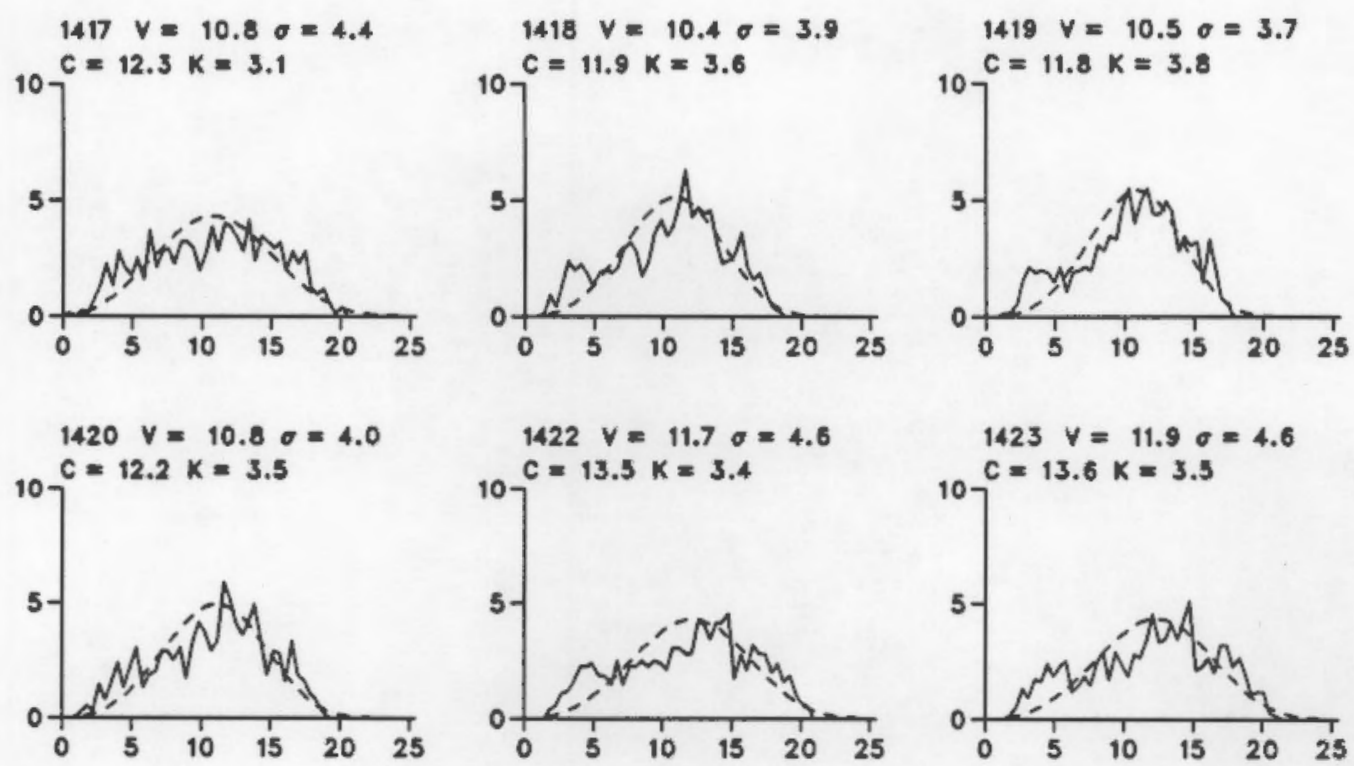

APPENDIX B

MODELED AND MEASURED WIND SPEED FREQUENCY DISTRIBUTIONS 


\section{APPENDIX B}

\section{MODELED AND MEASURED WIND SPEED FREQUENCY DISTRIBUTIONS}

In this appendix, modeled and measured wind speed frequency distributions are shown for all the stations in the NW and SW modeling domains. The modeled distributions are derived from the 30 model simulations of the wind flow, and these discrete distributions are represented as continuous density functions; the conversion between discrete and continuous distributions is described in Section 3.4.1. The actual distributions are formed from all 744 hours of data during the month of August, and these distributions are also represented in continuous form.

The distributions for the NW domain are shown first, followed by those for the SW domain. The station identification, station type (i.e., tuning or verification), and the observed and calculated mean monthly speed are listed above each plot. THE MODELED AND ACTUAL DISTRIBUTIONS ARE INDICATED BY SOLID AND DASHED LINES, RESPECTIVELY. 

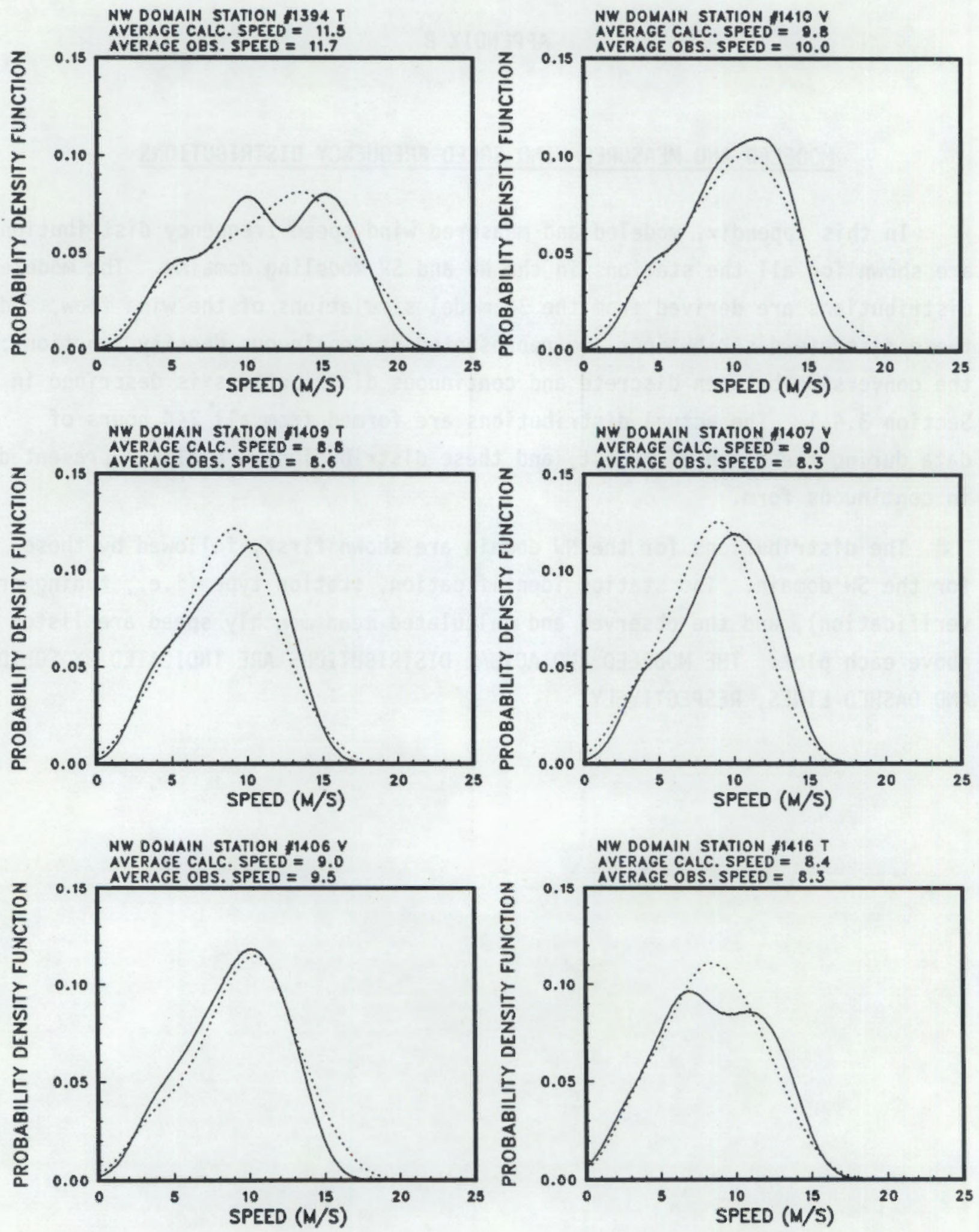

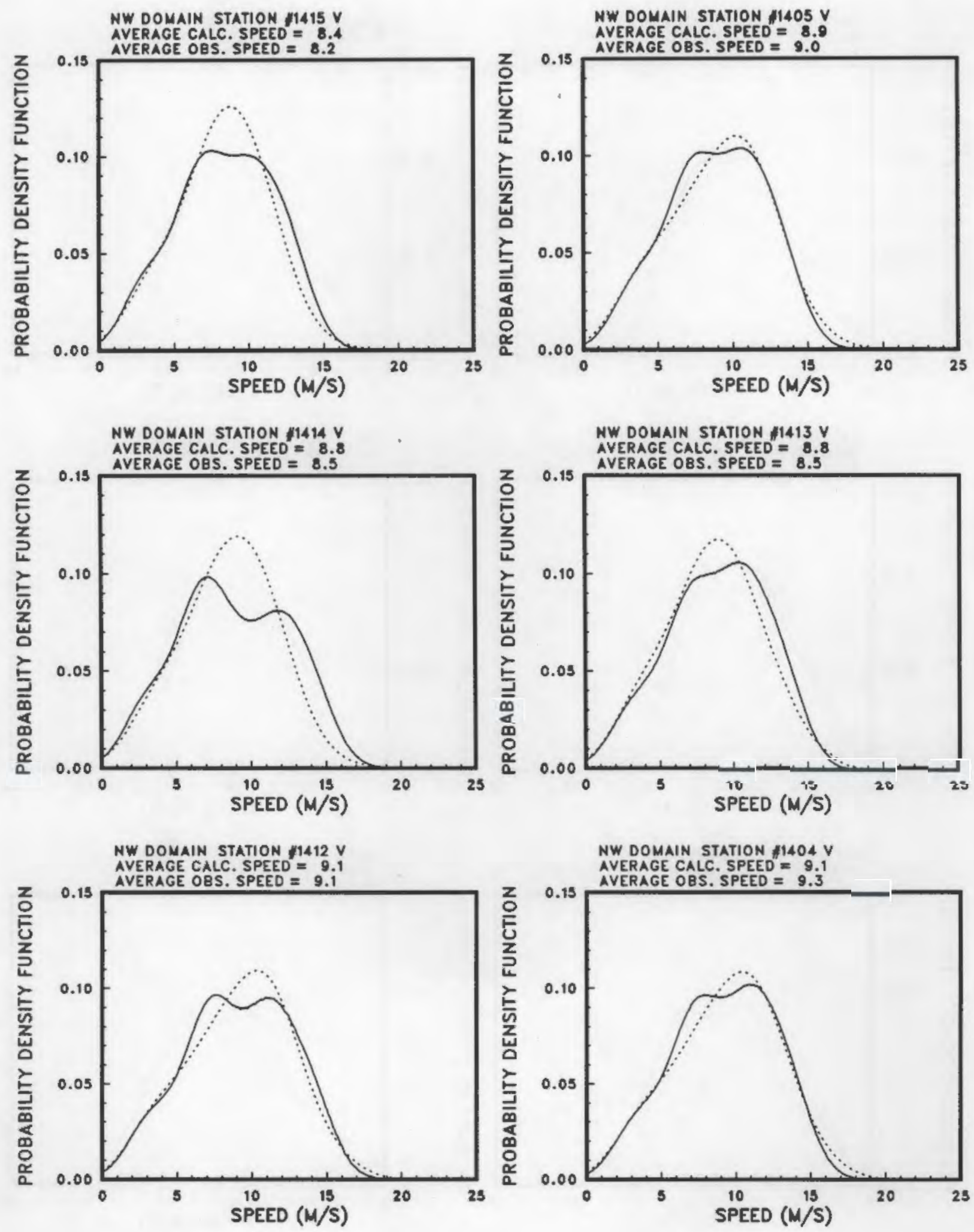

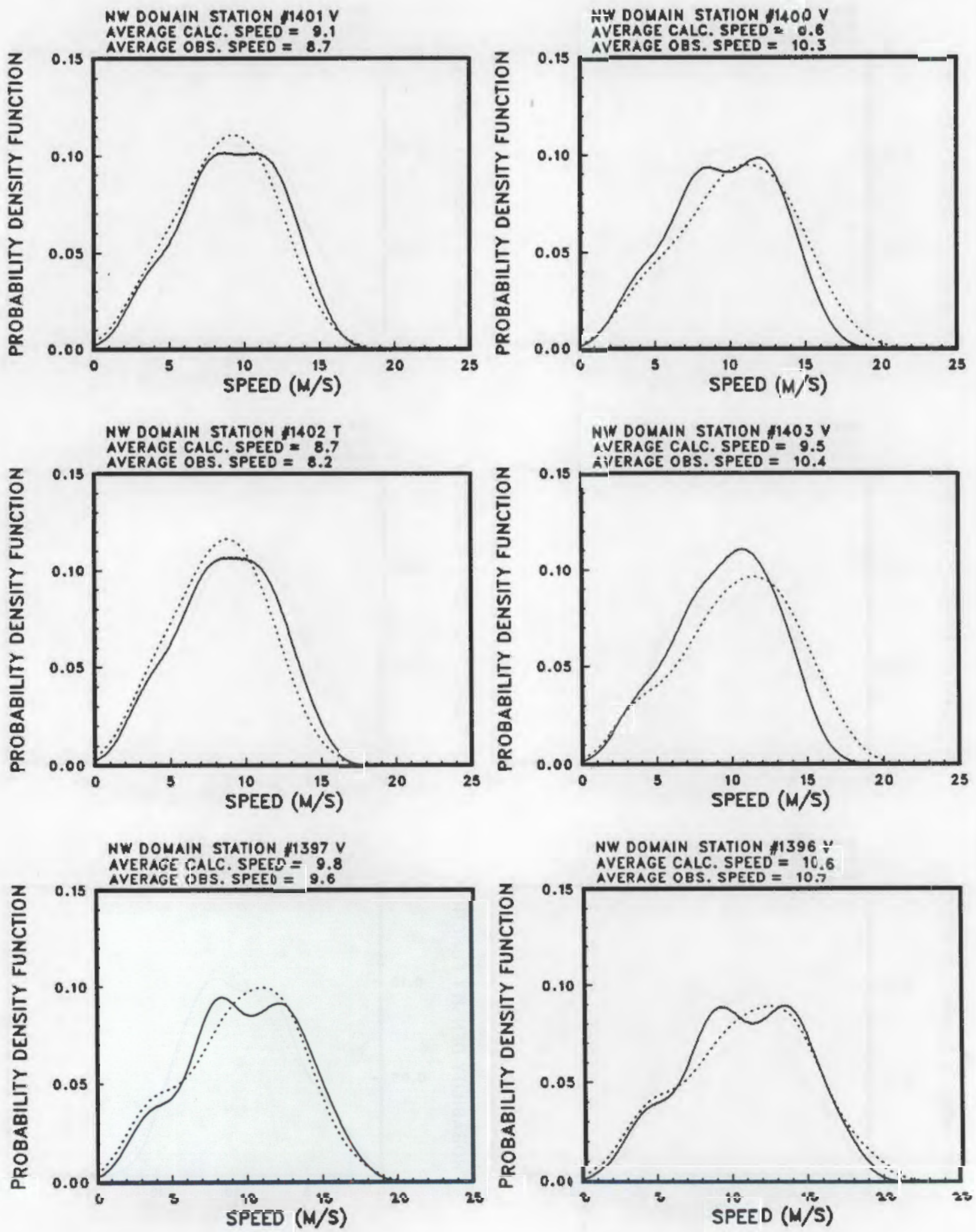

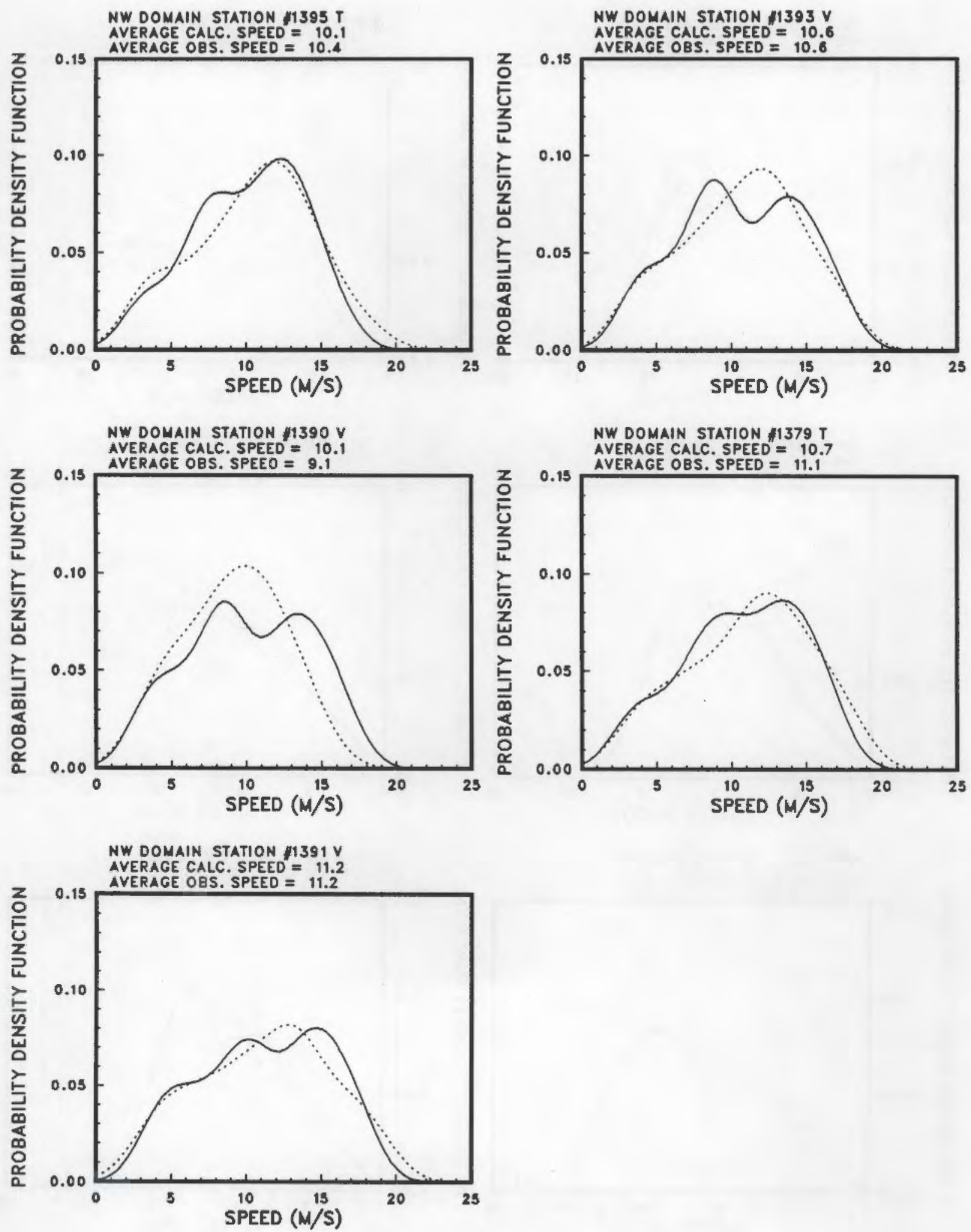

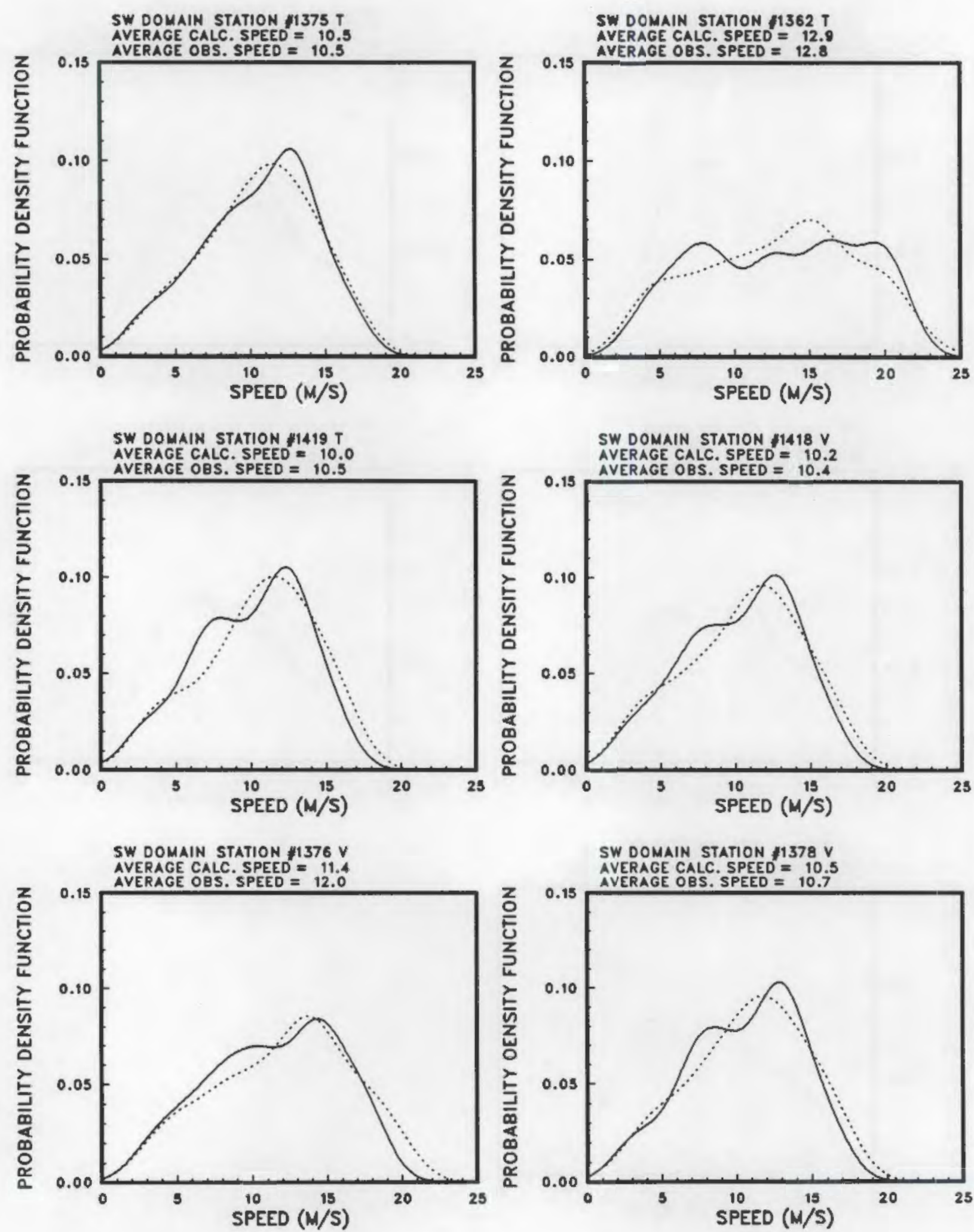

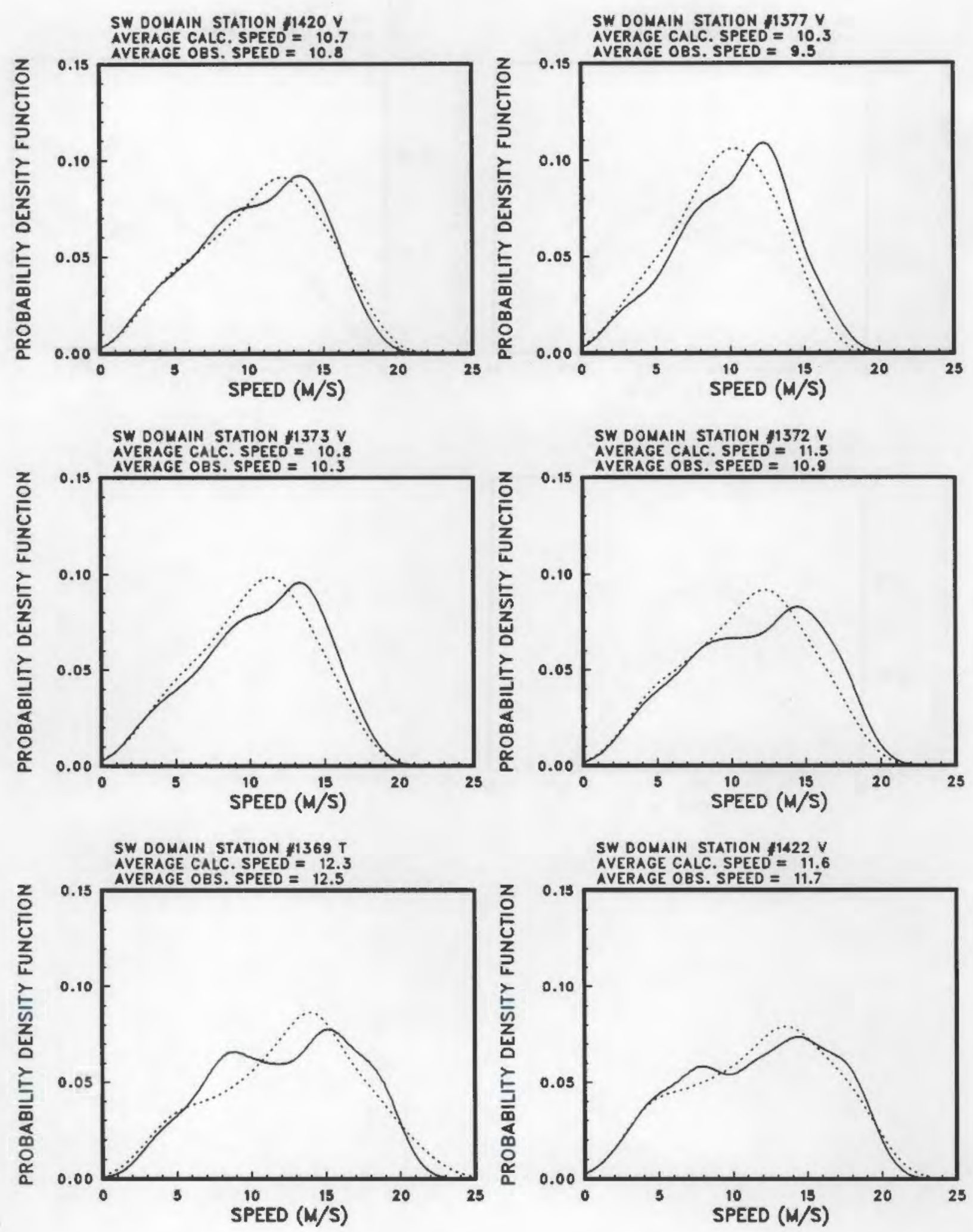

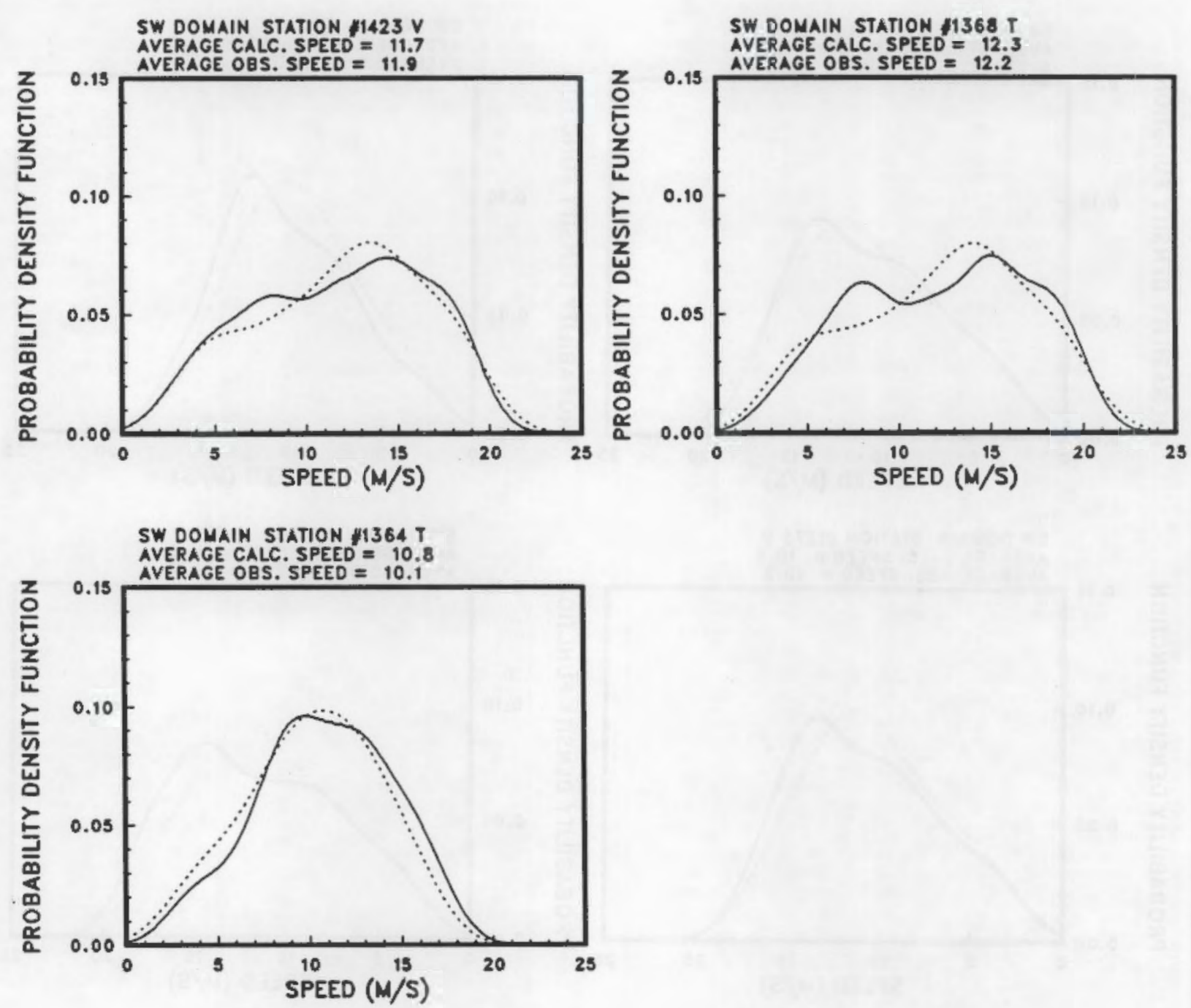


\section{DISTRIBUTION}

No. of

Copies

OFFSITE

C. I. Aspliden

Battelle Memorial Institute

Washington office

2030 M Street, NW

Washington, DC 20036

J. Cadogan

U.S. Department of Energy

Wind/Ocean Technologies Division 1000 Independence Avenue

Forrestal Building, Room $5 \mathrm{H} 048$

Washington, DC 20585

G. P. Tennyson

U.S. Department of Energy

Albuquerque Operations Office

P.0. Box 5400

Albuquerque, NM 87110

10 DOE Office of Scientific and

Technical Information

R. Baker

U.S. Windpower

6952 Preston Avenue

Livermore, CA 94550

W. Bollmeier

Solar Energy Research Institute

1617 Cole Boulevard

Golden, CO 80401

K. Cohn

Second Wind

880 Lombard Street

San Francisco, CA 94133

K. Cousineau

Zond Systems Incorporated

13000 Jameson Road

Tehachapi, CA 93561
No. of

Copies

E. Davis

U.S. Windpower

6952 Preston Avenue

Livermore, CA 94550

J. M. Fuchs

Fayette Manufacturing Corp.

P.0. Box 1149

Tracy, CA 95376

A. Germain

Flowind Corporation

1183 Quarry Lane

Pleasanton, CA 94566

R. H. Holeman

Bonneville Power Administration P.0. Box 3621

Portland, OR 97208

D. Kelley

Solar Energy Research Institute 1617 Cole Boulevard

Golden, CO 80401

P. B. S. Lissaman

AeroVironment, Inc.

825 Myrtle Avenue

Monrovia, CA 91016-3424

P. Liu

Flow Industries, Inc.

21414 68th Avenue, S.

Kent, WA 98032

R. Lynette

R. Lynette and Associates, Inc. 15032 N.E. 40th Street, Suite 206

Redmond, WA 98052

E. McCarthy

U.S. Windpower

6952 Preston Avenue

Livermore, CA 94550 
No. of

Copies

R. Nierenberg

Howden Wind Parks, Inc.

1330 Lincoln Avenue, Suite 310

San Rafael, CA 94901

D. Reda

Sandia National Laboratories

Division 6225

Albuquerque, NM 87185

R. Simon

434 Oakdale Avenue

Corte Madera, CA 94925

B. S. Smith

Grant Line Energy Corp.

15850 Jess Ranch Road

Route 5, Box 706

Tracy, CA 95376

D. A. Spera

NASA/Lewis Research Center

21000 Brookpark Rd.

Cleveland, $\mathrm{OH} \mathbf{4 4 1 3 5}$

W. Thompson

Fayette Manufacturing Corp.

P.0. Box 1149

Tracy, CA 95376

S. Veenhuizen

United Industries Corp.

12835 Bel-Red Road

Bellevue, WA 98005

P. Veers

Sandia National Laboratories

Applied Mechanics Div. IV

Albuquerque, NM 87185
No. of

Copies

J. Wade

Pacific Wind Energy

P.0. Box 1671

Corvallis, OR 97339

S. N. Walker

Pacific Wind Energy

P.0. Box 1671

Corvallis, OR 97339

ONSITE

DOE Richland Operations Office

J. J. Sutey/D. R. Segna

22 Pacific Northwest Laboratory

J. C. Barnard

J. W. Buck

J. R. Connell

D. W. Dragnich

C. E. Elderkin

D. L. Elliott

M. J. Graham

J. M. Hales

P. C. Hays

V. R. Morris

E. L. Owczarski

D. C. Powell

J. A. Stottlemyre

L. L. Wendell

R. E. Wildung

Publishing Coordination (2)

Technical Report Files (5) 